\title{
CONF-990401--
}

\section{EFFECT OF COLD WORK AND PROCESSING ORIENTATION ON THE SCC BEHAVIOR OF ALLOY 600}

W.C. Moshier and C.M. Brown

U.S. Department of Energy Contract DE-AC11-93PN38195

\section{NOTICE}

This report was prepared as an account of work sponsored by the United States Government. Neither the United States, nor the United States Department of Energy, nor any of their employees, nor any of their contractors, subcontractors, or their employees, makes any warranty, express or implied, or assumes any legal liability or responsibility for the accuracy, completeness or usefulness of any information, apparatus, product or process disclosed, or represents that its use would not infringe privately owned rights. 


\section{DISCLAIMER}

This report was prepared as an account of work sponsored by an agency of the United States Goverament. Neither the United States Government nor any agency thereof, nor any of their employees, makes any warranty, express or implied, or assumes any legal liability or responsibility for the accuracy, completeness, or usefulness of any information, apparatus, product, or process disclosed, or represents that its use would not infringe privately owned rights. Reference herein to any specific commercial product, process, or service by trade name, trademart, imanufacturer, or otherwise does not necessarily constitute or imply its endorsement, recommendation, or favoring by the United States Goyernment or any agency thereof. The views and opinions of authors expressed herein do not necessarily state or reflect those of the United States Governmeat or any agency thereof. 


\section{DISCLAIMER}

Portions of this document may be illegible in electronic image products. Images are produced from the best available original document. 


\title{
EFFECT OF COLD WORK AND PROCESSING ORIENTATION ON THE SCC BEHAVIOR OF ALLOY 600
}

\author{
W.C. Moshier and C.M. Brown \\ Bettis Atomic Power Laboratory \\ Westinghouse Electric Company \\ a division of CBS Corporation \\ West Mifflin, PA 15122-0079
}

\section{ABSTRACI}

Cold work accelerates SCC growth rates in Alloy 600 . However, the variation in crack growth rates generated from cold worked material has been significant, and the effect has been difficult to quantify. A study was performed in hydrogenated water adjusted to $\mathrm{pH} 10.2$ to systematically evaluate the effect of cold work on Alloy 600 as a function of temperature, amount of cold work, stress intensity factor, and processing orientation. Cold work was introduced into the material by either tensile prestraining or cold rolling plate product. Crack growth rates were determined between 252 and $360^{\circ} \mathrm{C}$, stress intensity factors between 21 and $55 \mathrm{MPa} / \mathrm{m}$, and yield strengths between 201 and $827 \mathrm{MPa}$. The material with the highest yield strength was cold rolled and tested in the longitudinal-transverse (LT) and short-transverse (ST) orientations. Crack growth rates increased with increasing temperature, stress intensity factor, and yield strength. Furthermore, crack growth rates were a strong function of the processing orientation in the cold rolled plate, with growth rates being approximately an order of magnitude greater in the ST orientation compared to the LT orientation. Crack growth rates in the LT orientation were measured between 0.003 and $1.95 \times 10^{-9}$ $\mathrm{m} / \mathrm{s}$ and between 0.066 and $6.3 \times 10^{-9} \mathrm{~m} / \mathrm{s}$ in the ST orientation. Activation energies were slightly greater in the ST orientation, ranging from 154 to $191 \mathrm{kcal} / \mathrm{mole}$, compared to activation energies between 126 and $157 \mathrm{~kJ} / \mathrm{mole}$ in the LT orientation. The results of this study demonstrate that although cold work can be used to accelerate SCC, the orientation of crack growth can significantly affect the results, and must be taken into account when analyzing data from cold worked material.

\section{INTRODUCTION}

Alloy 600 is susceptible to primary water stress corrosion cracking (SCC). Investigations of the crack growth rate behavior of Alloy 600 in primary water have shown that a number of variables impact cracking, including temperature, ${ }^{1-6}$ microstructure, ${ }^{4,6-8}$ carbon, ${ }^{3,9}$ electrolyte dissolved hydrogen concentration/electrochemical potential, ${ }^{3,10-12}$ stress intensity, ${ }^{2,46,9,13}$ and cold work or yield strength. ${ }^{1-3,5,6}$ The effect of temperature on SCC growth rates is well documented, and rates are typically plotted against reciprocal temperature to provide an Arrhenius relationship with a unique value for the process activation energy. This analysis has resulted in a range of activation energies $\left(65,{ }^{2} 74,{ }^{14} 80,{ }^{9} 138,{ }^{3} 168{ }^{9} \mathrm{~kJ} / \mathrm{mole}\right)$. The reason for the range in reported activation energies is not clear. In one case, the activation energy was reported to be dependent on the stress intensity, decreasing with increasing loading. ${ }^{9}$ Clearly, using an Arrhenius extrapolation of the crack growth rate (CGR) response to lower temperatures or longer times can lead to widely varying results, and variables other than temperature must play a significant role in the SCC growth behavior of Alloy 600.

Cold work has been used to accelerate SCC initiation and growth in Alloy 600, and must, therefore, play a significant roll in the SCC process. The amount of cold work has been demonstrated to have a strong effect on CGR in Alloy 600 . Bandy and Van Rooyen ${ }^{3}$ showed that introducing cold work in 
tubing by flattening the tube resulted in a factor of five increase in CGR over mill annealed tubing, as measured in a constant extension rate test. Shen and Shewmon ${ }^{15}$ compared CGRs for mill annealed Alloy 600 tested using a wedge opening loading (WOL) specimen, with data from Szklarska-Smialowska and coworkers, who measured CGRs using modified slow strain rate tests (SSRT) with cold pressed hump specimens. They found that CGRs increased by a factor of four when they compared the rates they obtained from their annealed material with the data from the cold worked material. Speidel and Magdowski ${ }^{2}$ found that increasing yield strength from 474 to $1053 \mathrm{MPa}$ by cold rolling bar stock resulted in a two orders-of-magnitude increase in CGRs, with measurable CGRs (of $3 \times 10^{-10} \mathrm{~m} / \mathrm{s}$ ) at temperatures as low as $200^{\circ} \mathrm{C}$. The CGRs reported by Speidel and Magdowski were measured in the $\mathrm{CL}$ orientation of the bar and are the highest rates that have been reported in the literature.

More recently, the effect of cold work on the SCC growth behavior of Alloy 600 was examined in detail on two heats of material taken from forged bars., ${ }^{5,6}$ Cold work was introduced by uniaxially straining the material orthogonal to the forging direction to several different levels of strain, and specimens were machined from the CL orientation. A region of Stage II crack growth was identified, where crack growth rates were independent of the stress intensity factor. In this regime, the most significant influence of cold work on CGR occurred in the first 5 percent of deformation, increasing less rapidly with increasing cold work. Increasing yield strength from 470 to $880 \mathrm{MPa}$ resulted in an increase in CGR by a factor of four: Activation energy for SCC growth between 290 and $350^{\circ} \mathrm{C}$ was determined to be $130 \mathrm{~kJ} / \mathrm{mole}^{6}$

Clearly, cold work affects the SCC behavior of Alloy 600 . However, confusion exists as to how cold work plays a role in accelerating SCC growth. Developing the understanding on how cold work affects SCC growth is important, because it may be possible to use cold work not only to provide useful data at low temperatures in a relatively short period of time, but also to provide an insight into the mechanism that is driving primary water SCC. In this paper, the effect of cold work on plate product is systematically evaluated to quantify its effect on SCC growth. The effect of cold work was evaluated with both bolt loaded and actively load specimens machined in the LT orientation and loaded to a single stress intensity factor $(\sim 33 \mathrm{MPa} \sqrt{\mathrm{m}})$. The effect of stress intensity factor and processing orientation (ST, LT) on CGRs were evaluated on cold rolled plate, which had a yield strength of $827 \mathrm{MPa}$.

\section{EXPERIMENTAL}

\section{Materials}

The material used in this study was from a single heat (NX5853G11) of Alloy 600. The composition of the plate is listed in Table 1. The plate, which originally measured $538 \mathrm{~cm} \times 220 \mathrm{~cm} \times 5.33 \mathrm{~cm}$, was cut into sections for this study. An arrow marking the rolling direction of the original plate was placed on each section to maintain traceability. Three general types of materials processing were performed on the plate to obtain the different types of test specimens required for this program. These included:

Annealed Material - As-heat treated specimens received a vacuum anneal at $1075^{\circ} \mathrm{C}$ for 24 hours, followed by a controlled 24 hour furnace cool.

Uniformly Strained Material - Two separate $61 \mathrm{~cm}$ x $122 \mathrm{~cm}$ sections of plate were machined into eight large tensile bars, each having a $38.1 \mathrm{~cm}$ long reduced width gage section and $7.62 \mathrm{~cm}$ wide full width grip sections on each end. These large tensile bars were heat treated in a vacuum furnace at $1075^{\circ} \mathrm{C}$ for 24 hours with a $2.5 \mathrm{~cm}$ minimum gap between each bar, followed by a controlled furnace cool in argon to ambient temperature over 24 hours. After heat treating, the tensile bars 
were strained in the $L$ orientation at room temperature in a 4.45 MN hydraulic test machine using wedge grips to four different levels of tensile strain.

Cold Rolled Material - A $30.5 \mathrm{~cm} \times 30.5 \mathrm{~cm} \times 5.3 \mathrm{~cm}$ section of plate was heat treated in argon gas at $1075^{\circ} \mathrm{C}$ for 24 hours and then furnace cooled. The plate was then cold rolled to produce a 31.9 percent reduction in thickness. The final thickness was $3.63 \mathrm{~cm}$ with a final width of $39.4 \mathrm{~cm}$ and length of $69.3 \mathrm{~cm}$. The reduction was performed in 15 passes with 5 passes in the cross direction to reduce bowing. A final flattening operation was performed to eliminate bowing that developed during rolling.

The microstructure that resulted from the heat treatment was assessed by polishing the specimen and electrolytically etching the surface in orthophosphoric acid, repolishing the specimen, and electrolytically etching the surface in nitric acid/methanol solution. The orthophosphoric etch revealed grain morphology and carbide distribution, whereas the nitric acid etch revealed general microstructure, including grain boundaries.

The heat treatment resulted in a banded microstructure, which consisted of alternating regions of relatively large grains, surrounded by bands of small grains as shown in Figure 1 . The grain boundaries of both regions are precipitated almost continuously with discrete carbides. A cross-section of the transverse orientation of the plate is shown in Figures 2 and 3 . Extensive networks of intragranular carbides were also found in the fine grains, which had formed on the grain boundaries that were present prior to annealing and outline a ghost grain structure. The difference in grain size between the coarse and fine grain region was significant. Coarse grains were as large as $250 \mu \mathrm{m}$, whereas the typical grain size in the fine grain area was closer to $55 \mu \mathrm{m}$.

Tensile and compact tension specimens were machined from each condition. In the case of the uniformly strained material, specimens were taken from the gage length. Specimens machined from the cold rolled plate were taken near the center thickness of the plate, where the hardness remained uniform. The mechanical properties of each product can be found in Table 2.

\section{Test Method}

Several different types of compact tension specimens were used in this study. Specimens were machined to a wedge opening loading (WOL) design [thickness (B) of $2.032 \mathrm{~cm}$, width (W) of 5.181 $\mathrm{cm}$, and a height-to-width ratio (HM) of 0.486] for actively loaded tests or compact tension (C(T)) specimens $[B=2.032$ or $1.016 \mathrm{~cm}, W=4.064$ or $2.032 \mathrm{~cm}, \mathrm{H} / \mathrm{W}=0.6]$ for bolt loaded tests. The smaller $C(T)$ specimen was required because the final thickness of the cold rolled plate precluded the use of a larger ST-oriented specimen. Each compact tension specimen was precracked in air at a stress ratio, $R$, equal to 0.1 and a loading cycle frequency of $30 \mathrm{~Hz}$ in a series of decreasing load increments. The final maximum stress intensity factor, $K_{\max }$, for the WOL and larger $C(T)$ specimens was $20 \mathrm{MPa} \sqrt{\mathrm{m}}$, and either 11 or $16 \mathrm{MPa} \sqrt{\mathrm{m}}$ for the smaller $\mathrm{C}(\mathrm{T})$ specimens. Specimens precracked at the lower $\mathrm{K}$ values were tested below $38 \mathrm{MPa} \sqrt{\mathrm{m}}$. The initial crack length was measured both visually and with microfocus X-ray and compared to the crack length after each inspection to help determine whether the crack was growing.

The load on the bolt loaded $C(T)$ specimen was determined using a load transfer technique. ${ }^{16}$ The specimens were loaded to 96 percent of the final load in a tensile machine, and the load was then transferred to the bolt in a series of steps while the crack mouth opening displacement (CMOD) was maintained constant. The final target load was achieved by tightening the bolt in the specimen to obtain the correct CMOD. The bolt material was Alloy $\mathrm{X}-750$, which was coated with neolube (graphite suspension in alcohol) to minimize galling. The larger specimens were loaded to $33 \mathrm{MPa} \sqrt{\mathrm{m}}$, and the smaller specimens were loaded to a $\mathrm{K}$ between 22 and $55 \mathrm{MPa} \sqrt{\mathrm{m}}$. Specimens 
removed for destructive examination were unloaded using the load transfer technique in reverse to measure the remaining load on the specimen.

Active load testing involved applying a load to a train of four specimens with a servohydraulic actuator. The load on the specimens was held constant for a period of time, and periodically cycled to infer a value of the crack length through a compliance measurement. A linear variable differential transducer (LVDT) was attached to the front face of each specimen to measure crack mouth opening displacement. Specimens were held at a constant load for either 10 or 100 minutes, and then unloaded and reloaded over a period of 1 minute with a load ratio of 0.7 using a triangular waveform. This periodic unloading was used in an attempt to measure the time required to incubate cracking. At the completion of the test, the specimens were destructively examined to assess the amount of crack growth that had occurred on each specimen.

\section{Environmental Testing Conditions}

Testing was conducted in 31-liter stainless steel autoclaves that were continuously refreshed from a holding tank at a rate between $10-50 \mathrm{ml} / \mathrm{min}$. The test environment was hydrogenated water adjusted to a pH of 10.2. Bolt loaded testing was performed at five different temperatures: 252,288 , 316,338 , and $360^{\circ} \mathrm{C}$, whereas active loaded specimens were only tested at 316 and $338^{\circ} \mathrm{C}$. Axial temperature uniformity in the autoclave at the test flow conditions did not vary more than $1^{\circ} \mathrm{C}$ in the region where the specimens were located. The autoclave pressure was $19.6 \mathrm{MPa}$ for the bolt-load specimen tests and above $13.8 \mathrm{MPa}$ for the active-load specimen tests.

Water chemistry was monitored periodically during the test for dissolved oxygen, dissolved hydrogen, conductivity, $\mathrm{pH}$ and contaminants. Room temperature $\mathrm{pH}$ ranged between 10.2 and 10.3 , and rarely fell outside this range. Conductivity was maintained between 35 and $45 \mu \mathrm{S} / \mathrm{cm}$ by controlling $\mathrm{pH}$.

Dissolved gases were monitored throughout the test. Dissolved oxygen was typically $<10 \mathrm{ppb}$, but occasionally exceeded $15 \mathrm{ppb}$. Dissolved hydrogen ranged between 3.3 to $4.9 \mathrm{ppm}$, and averaged near $4.1 \mathrm{ppm}$. In the case of the bolt-loaded specimens, dissolved hydrogen had to be reduced in the autoclave to $\sim 1.4 \mathrm{ppm}$ during startup or cool down, to eliminate the concern for low temperature cracking. The amount of time that the specimens resided at lower levels of dissolved hydrogen was kept to a minimum.

Total organic carbon (TOC) and selected ion concentrations were measured periodically throughout the test to assess test cleanliness. TOCs were measured using a total organic carbon analyzer, and were generally nondetectable $(<0.1 \mathrm{ppm}$ ) during a test. The concentration of several different anions were measured using ion chromatography, including chloride, nitrate, nitrite, phosphate, sulfate, and sulfite, and occasionally fluoride. Total ion concentrations were also measured using inductively coupled plasma spectroscopy and included $\mathrm{Sn}, \mathrm{Fe}, \mathrm{Cr}, \mathrm{Ni}, \mathrm{Pb}, \mathrm{Zn}, \mathrm{Cu}, \mathrm{Mg}, \mathrm{Mn}, \mathrm{Ca}, \mathrm{Co}$, $\mathrm{Ti}, \mathrm{Al}, \mathrm{Mo}, \mathrm{S}, \mathrm{P}$, and $\mathrm{Na}$. Contaminants that were typically found in the water were $\mathrm{Ca}, \mathrm{Si}, \mathrm{Al}, \mathrm{Mg}$, (10-30 ppbs) and occasionally $\mathrm{Cl}$ ions (50-100 ppb). $\mathrm{Ca}, \mathrm{Si}, \mathrm{Al}$, and $\mathrm{Mg}$ have been associated with material leaching from the zirconia that is used to electrically isolate the specimens. In most cases, the specimens were isolated from autoclave ground during the test by either hanging the bolt-loaded specimens from Transition Toughened Zirconia (TTZ) rods or using TTZ spacers on the loading pins of the actively loaded specimens. Chloride has generally been associated with the release of $\mathrm{KCl}$ from the $\mathrm{Ag} / \mathrm{AgCl} / 0.1 \mathrm{~N} \mathrm{KCl}$ reference electrodes that were used in each test. Other contaminants that were sporadically found in the test were $\mathrm{Fe}$ and $\mathrm{S}$. The $\mathrm{S}$ concentration was significant in some measurements, but subsequent measurements showed no $S$ present, and the source of $S$ could not be isolated. Autoclaves that experienced measurable levels of contaminants were flushed to drain and the solution in their holding tanks replaced to reduce the contaminant concentration. This technique was very successful at rapidly reducing the level of contaminants in the autoclave. 


\section{Crack Characterization}

The majority of the specimens removed from the test were cyclically loaded to failure in air at an initial maximum load (Pmax) of 50 percent of the residual bolt load and an $R=0.3$ at a frequency of $30 \mathrm{~Hz}$ to minimize damage to the SCC fracture surface. In some cases, the stress corrosion crack extended almost to the back face of the specimen, and these specimens were simply pulled apart. Specimens were typically cross-sectioned through their thickness to provide information on both the fracture surface and crack path. In the case of the smaller $C(T)$ specimens, the surfaces were polished and etched prior to fatigue loading the specimen to failure to examine the fracture surface. Cross-sections were polished and etched with a nitric acid/methanol solution, which preferentially etched grain boundaries, to help determine the mode of cracking. In addition, these specimens were heat tinted prior to being fatigued apart because of the difficulty of precisely determining the SCC region, particularly in the case of the ST oriented specimens. Crack extension was measured by averaging nine points along the crack front. Optical and scanning electron microscopy (SEM) examinations of the fracture surfaces were performed to document and characterize the fracture morphology.

\section{RESULTS}

Examination of the specimens that were removed from test showed that in most cases the fracture path was almost entirely intergranular. Examination of the fracture surface on most of the cold worked specimens revealed well defined grain facets that were decorated with carbides as shown in Figure 4. Figure 5 shows that the carbides took two forms, with some of the carbides being blocky and others having a dendritic structure. The fracture surface of the cold rolled material had grains that were very elongated, which was not evident in the tensile strained material. Polished and etched cross sections of the SCC region showed that the crack followed grain boundaries in the tensile strained material. A typical example of this behavior is shown in Figure 6 for the uniaxially tensile prestrained material and in Figure 7 for the cold rolled material. In general, the stress corrosion crack continued to grow in the plane of the precrack, although well-defined crack branching did occur in several specimens, and these cracks also grew intergranularly.

An exception to the intergranular crack growth occurred in several specific cases. Actively loaded specimens with the 10 minute hold period showed evidence of isolated regions of transgranular fracture. The same behavior was also evident for cold rolled bolt-loaded specimens that had been machined in the LT orientation. In this case, Figure 8 shows that cracks periodically grew transgranularly before linking back up with grain boundaries. The cracking mode was predominately intergranular for bolt-loaded cold rolled specimens tested in the ST orientation above $288^{\circ} \mathrm{C}$. However, for the cold rolled material tested in the ST orientation at $288^{\circ} \mathrm{C}$ and stress intensity factors less than $40 \mathrm{MPa} \sqrt{\mathrm{m}}$, Figure 9 shows that the cracking mode was predominately transgranular. The reason for the shift in the fracture mode is not known, but a similar trend has been noted in slow strain rate tests performed at $288^{\circ} \mathrm{C} .^{1}$

The transgranular fracture surface from a specimen tested in the ST orientation is shown in Figure 10 and is rough, covered by features that appear to be fractured "particles." The dimensions of these particles did not correspond with the carbide distribution or morphology. Closer examination of the "particle" morphology shows that they have an appearance of poorly defined facets. Note in Figure 10 that the particles are aligned with the crack growth, and continue across the fracture surface, being broken up by what may be narrow slip offsets. This type of fracture is unusual, being more typical of fatigue that occurs at low stress intensities, and may be the result of the limited number of slip systems that remain active after the severe level of cold work induced during cold rolling. 
Tables 3 and 4 provide a tabulation of the crack growth rate results for the specimens tested in this study. These data were determined from the post-test destructive examination of each specimen by dividing the average crack extension by the total time in test. Crack growth rate data obtained in the LT orientation contains results from both active and bolt-loaded specimens. In most cases, the effect of load cycling on crack growth rate was small, and became more significant at lower yield strengths. For specimens tested at 316 and $338^{\circ} \mathrm{C}$, Figure 11 shows that the crack growth rates measured at longer hold times were more consistent with the rates determined from the bolt-loaded specimens. At $288^{\circ} \mathrm{C}$, Figure 12 shows that increasing the cyclic loading frequency did increase the crack growth rate, although the effect was typically close to a factor of two. The reason that cyclic loading at higher temperatures had less influence on the crack growth rate may be that the rate for the SCC process on the cold worked material greatly exceeded the driving force for fatigue crack propagation. At lower temperatures, the propagation rate for fatigue becomes comparable to the SCC rate, and begins to influence the crack growth.

\section{DISCUSSION}

Several factors can affect the SCC behavior of Alloy 600 . In this study, the effects of cold work, stress intensity factor, and orientation were individually evaluated. To evaluate each effect, testing was performed to provide sufficient data to evaluate one parameter while holding the others constant. Factors other than cold work, stress intensity factor, and orientation have also been reported to influence $S C C$, such as microstructure, the presence of dissolved hydrogen in the environment, and carbon concentration. These variables were held constant by evaluating only one heat in a single, well-controlled environment to minimize their effect on the results of this work.

\section{Effect of Cold Work}

The effect of cold work on SCC was examined for material tested in the LT orientation. Crack growth rates from bolt-loaded and actively-loaded specimens were measured on both the tensile prestrained and cold rolled materials between 360 and $288^{\circ} \mathrm{C}$ over a narrow band of stress intensity factors between 28 and $35 \mathrm{MPa} \sqrt{\mathrm{m}}$. The data is plotted as a function of the yield strength and is shown in Figure 13, which illustrates that the crack growth rate in the LT orientation is a function of cold work, with the crack growth rate related to the yield strength as Equation 1:

$$
\dot{a}=\dot{a}_{0} e^{\alpha \sigma}
$$

where $\alpha$ is between 0.0040 and $0.0047 \mathrm{Mpa}^{-1}$, and $\sigma$ is the material's yield strength. The significant amount of scatter in the CGR data led to a low correlation coefficient below $360^{\circ} \mathrm{C}$. However, the value of $\alpha$ determined at the lower temperatures remains close to the value measured at $360^{\circ} \mathrm{C}$. These results compare to the work by Vaillant et al., which showed a similar relationship between yield strength and crack growth rate. ${ }^{6}$ However, the value of a reported by Vaillant et al. varied as a function of cold work, with a larger value of $0.0079 \mathrm{MPa}^{-1}$ for material cold worked to a yield strength of $475 \mathrm{MPa}$, and decreasing to $0.0023 \mathrm{MPa}^{-1}$ at higher levels of cold work. The smaller value of $\alpha$ would indicate that the effect of cold work on SCC growth behavior of the material tested in this study was less severe at lower yield strengths. This may be due in part to differences in the carbon concentration, which was lower for the material tested in Reference 6, and should increase the material's susceptibility to SCC. ${ }^{3}$ It may also be due to the product form, where CGRs in plates have been reported to be slower than in forgings. ${ }^{4}$

\section{Effect of Stress Intensity Factor}

The effect of stress intensity factor was evaluated for specimens tested in both the LT and ST orientations on material cold rolled to a yield strength of $827 \mathrm{MPa}$. In the case of specimens tested 
in the ST orientation, the crack growth rate was found to be dependent on the stress intensity factor to which the specimen was loaded, as shown in Figure 14. Between a range in K of 21 and 55 $\mathrm{MPa} \sqrt{\mathrm{m}}$, the crack growth rate remained a slight function of $\mathrm{K}$, with the form of:

$$
\dot{a}=\dot{a}_{0} e^{\beta K}
$$

where $\beta$ varied from 0.05 to $0.055(\mathrm{MPa} \sqrt{\mathrm{m}})^{-1}$ between 288 and $338^{\circ} \mathrm{C}$. Although the dependence on $\mathrm{K}$ is small, these results indicate that the crack growth rate is dependent on the stress intensity factor in a region that has often been identified as Stage II growth, i.e., the crack growth rate is independent of the specimen loading. This effect translates to the LT orientation, as shown in Figure 15. A comparison of the crack growth rates at $316^{\circ} \mathrm{C}$ between the two orientations shows that the dependence of the crack growth rate on the stress intensity factor is similar, i.e., $\beta$ determined from specimens tested in the LT orientation is $0.049(\mathrm{MPa} \sqrt{\mathrm{m}})^{-1}$.

\section{Effect of Orientation}

The effect of the original material processing and subsequent cold working directions on the SCC behavior of Alloy 600 has almost been completely ignored in the literature. Cold work has been used to evaluate whether SCC is dependent on material yield strength. Although the original processing orientation has usually been noted, materials were often cold worked in an orientation that is not consistent with the direction in which they were processed. Hence, the impact of the original processing orientation on the SCC behavior of the material is often obscured by introducing cold work for the sole purpose of increasing yield strength. In this study, both tensile pre-straining and cold rolling were performed along the original rolling direction of the plate. The effect of orientation on the SCC growth behavior of Alloy 600 that arises from cold rolling was significant, as shown in Figure 15. At $316^{\circ} \mathrm{C}$, the crack growth rate is a factor of eight greater in the ST orientation than in the LT orientation. This difference between the ST and LT orientations diminished at lower temperatures, although the crack growth rate was always greater in the ST orientation.

A comparison of the CGRs measured at $288^{\circ} \mathrm{C}$ for the cold rolled plate tested in the ST orientation with the cold rolled bar tested in the $\mathrm{CL}$ orientation and reported by Speidel and Magdowski ${ }^{2}$ is shown in Figure 16. The differences in yield strength between the plate and bar were 827 and $981 \mathrm{MPa}$, respectively. Data obtained in the $\mathrm{CL}$ orientation in the bar, which was cold rolled along the axial direction, would be expected to provide results similar to the ST orientation in plate because in both cases crack growth is along a plane in the material that has experienced similar types of deformation. The results show that the crack growth rates for the plate lie below the bar, and that the value of $\beta$ for the bar is slightly less than the plate. The difference in the crack growth rate could be accounted for, in part, as a result of the difference in yield strength. These results indicate that increasing yield strength reduces the effect of the stress intensity factor on the crack growth rate, which would indicate that the effect of the stress intensity factor and yield strength on crack growth rate are interdependent.

\section{Activation Energy}

The effect of crack growth orientation can evaluated for the LT and ST orientations, holding both $K$ and yield strength constant. Activation energies were only determined if sufficient data was available at three temperatures. In the case of the LT orientation, activation energies were determined at several different levels of cold work at approximately a single value of stress intensity ( $33 \mathrm{Mpa} / \mathrm{m}$ ). Crack growth rates from cold rolled (827 MPa) and uniaxially strained (630 and $515 \mathrm{Mpa}$ ) material were used to determine activation energy as a function of yield strength. Figure 17 shows that the activation energy for the cold rolled material was $126 \mathrm{~kJ} / \mathrm{mole}$ and 138 and $158 \mathrm{~kJ} / \mathrm{mole}$ for the uniaxially strained material, and systematically decreased as the yield strength increased. This trend 
of decreasing activation energy with increasing yield strength is consistent with the behavior reported in Reference 1. In the case of crack growth rates determined in the ST orientation on cold rolled material, the activation energies were determined at three different stress intensity factors of 21,33 and $40 \mathrm{MPa} \sqrt{\mathrm{m}}$. Figure 18 shows activation energies determined from the cold rolled material were not a strong function of $\mathrm{K}$, providing values of 151,184 , and $149 \mathrm{~kJ} / \mathrm{mole}$. This result is significantly different from Shen and Shewmon, who reported that the activation energy was a strong function of

$\mathrm{K}^{9}$. This difference may be a result of the difference in the materials yield strengths between the cold rolled plate used in this study and the annealed plate used in Reference 9.

Activation energies in the LT orientation are slightly lower than in the ST orientation, although the difference is small. This result would indicate that the process controlling crack growth in the two orientations is probably similar, although the rate of crack growth is significantly different. In addition, ignoring the effect of orientation and combining all of the CGR data would lead to erroneous values for the activation energy. Therefore, material processing direction and orientation should be taken into account when analyzing data to determine the activation energy.

\section{CONCLUSIONS}

This work demonstrates that processing orientation is an important factor in affecting the crack growth rate of cold worked material. Yield strength and stress intensity factor also have an effect. Although the effect of yield strength is well documented in the literature, the effect can vary significantly depending on how the cold work is introduced as well as the orientation in which the crack grow. Crack growth rates were an order of magnitude greater in the ST orientation compared to the LT orientation. It is not clear how this effect varies with the amount of cold rolling, or whether other forms of cold work have a similar effect on SCC behavior. The effect of orientation is very likely the cause for the high crack growth rates reported in Reference 2.

Crack growth rates decreased at lower stress intensity factors for material tested in either the LT or ST orientations over a range of stress intensity factors that are often identified as Stage II growth, where growth should not be dependent on stress intensity factor. Comparison of the crack growth rate data in the ST orientation to literature data indicates that as the yield strength of the material increases, the dependence of crack growth rate on the stress intensity factor should decrease.

The fracture mode of the specimens tested in the ST orientation varies as a function of stress intensity factor and temperature. At temperatures above $316^{\circ} \mathrm{C}$, the fracture mode was predominately intergranular. Below $316^{\circ} \mathrm{C}$ for specimens loaded to a stress intensity factor less than $44 \mathrm{MPa} / \mathrm{m}$, cracking was predominately transgranular. This result was for highly cold rolled Alloy 600 , and annealed Alloy 600 tested at low temperatures may have a different fracture behavior.

Activation energies ranged between 154 and $191 \mathrm{~kJ} /$ mole for cracks growing in the ST orientation and between 126 and $158 \mathrm{~kJ} /$ mole for cracks growing in the LT orientation. Activation energies were measured between 288 and $338^{\circ} \mathrm{C}$ in the ST orientation and between 316 and $360^{\circ} \mathrm{C}$ in the LT orientation. The overlap in the range of activation energies measured in the two orientations would indicate that the process controlling crack growth is similar, although the rate of crack growth is significantly different.

\section{ACKNOWLEDGEMENTS}

This work was performed on DOE contract DE-AC11-93PN38195. The authors would like to gratefully acknowledge the technical assistance of P. Farren, G. Smith, G. Hoffman, B. Whitmore and K. Linhart. 


\section{REFERENCES}

1) R.B. Rebak, Z. Xia, Z. Szklarska-Smialowska, Corrosion 51, 9 (1995): p. 689.

2) M.O. Speidel and R. Magdowski, "Stress Corrosion Cracking of Nickel Base Alloys in High Temperature Water," Proc. 6th Int'l. Symp. Environmental Degradation of Materials in Nuclear Power Systems - Water Reactors (Warrendale, PA; TMS 1993), p. 361.

3) R. Bandy and D. Van Rooyen, Corrosion 40, 8 (1984): p. 425.

4) W. Bamford and J. Foster, "Alloy 600 Penetration Crack Growth Rate Program and Results," Electric Power Research Institute PWSCC Workshop, Nov 15-17, 1994, Tampa, FL.

5) R. Magdowski, F. Vaillant, C. Amzallag, and M.O. Speidel, "Stress Corrosion Crack Growth Rates of Alloy 600 in Simulated PWR Coolant," Proc. 8th Int'l. Symp. Environmental Degradation of Materials in Nuclear Power Systems - Water Reactors (La Grange, IL; ANS 1997), p. 333.

6) F. Vaillant, C. Amzallag, and J. Champredonde, "Crack Growth Rate Measurements of Alloy 600 Vessel Head Penetrations," Proc. 8th Int'l. Symp. Environmental Degradation of Materials in Nuclear Power Systems - Water Reactors (La Grange, IL; ANS 1997), p. 357.

7) G. S. Was and K. Lian, Corrosion 54, 9 (1998), p. 675.

8) J.K. Sung and G.S. Was, Corrosion $47,11(1991)$, p. 824

9) Y. Shen and P. G. Shewmon, Corrosion 47, 9 (1991), p. 712.

10) N. Totsuka and Z. Szklarska-Smialowska, Corrosion 43,12 (1987), p. 734

11) N. Totsuka, E. Lunarska, G. Cragnolino, and Z. Szklarska-Smialowska, Corrosion 43, 8 (1987): p. 505.

12) G.S. Was, J.K. Sung, and T.M. Angeliu, Metall. Trans. A 23A, (1992): p 3343.

13) R. B. Rebak and Z. Szklarska-Smialowska, Corrosion 50, 5 (1994), p. 378.

14) N. Totsuka and Z. Szklarska-Smialowska, Scripta Metall. 41 (1987), p. 45.

15) C.H. Shen and P.G. Shewmon, Metall. Trans. A 21A, (1990), p. 1261.

16) W.J. Mills, "Effect of Irradiation on the Stress Corrosion Cracking Behavior of Alloy X-750 and Alloy 625," Proc. Sixth International Symposium on Environmental Degradation of Materials in Nuclear Power Systems - Water Reactors (La Grange, IL; ANS 1993), pp. 633-643. 


\begin{tabular}{||c|c|c|c|c|c|c|c|c|c|c|c|c||}
\hline \multicolumn{10}{|c|}{$\begin{array}{c}\text { Table 1. Composition of Heat NX5853G11 } \\
\text { (weight percent unless otherwise noted) }\end{array}$} \\
\hline & $\mathrm{C}$ & $\mathrm{Mn}$ & $\mathrm{Fe}$ & $\mathrm{S}$ & $\mathrm{Si}$ & $\mathrm{Cu}$ & $\mathrm{Ni}$ & $\mathrm{Cr}$ & $\mathrm{Al}$ & $\mathrm{Ti}$ & $\mathrm{Mg}$ & $\mathrm{Co}$ \\
\hline $\begin{array}{c}\text { Material } \\
\text { Cert. }\end{array}$ & 0.07 & 0.25 & 7.76 & $<0.001^{\star}$ & 0.22 & 0.11 & 75.55 & 15.46 & 0.18 & 0.34 & 0.01 & 0.04 \\
\hline $\begin{array}{c}\text { Independent } \\
\text { Analysis }\end{array}$ & 0.063 & 0.26 & 7.61 & $<0.001^{\star}$ & 0.23 & 0.12 & 75.51 & 15.35 & 0.17 & 0.35 & 0.014 & 0.056 \\
\hline & $\mathrm{B}$ & $\mathrm{P}$ & $\mathrm{Mo}$ & $\mathrm{Ta}$ & $\mathrm{Zr}$ & $\mathrm{Cb}$ & $\mathrm{O}$ & $\mathrm{N}$ & $\mathrm{H}$ & $\begin{array}{c}\mathrm{Sb} \\
\text { (ppm) }\end{array}$ & $\begin{array}{c}\text { As } \\
\text { (ppm) }\end{array}$ \\
\hline $\begin{array}{c}\text { Material } \\
\text { Cert. }\end{array}$ & 0.008 & 0.003 & & & & & & & & & \\
\hline $\begin{array}{c}\text { Independent } \\
\text { Analysis }\end{array}$ & 0.005 & $* \star$ & 0.11 & $<0.003^{\star}$ & $<0.002^{\star}$ & 0.12 & 0.002 & 0.007 & 3 & $<10$ & $<10$ \\
\hline
\end{tabular}

* Not Detectable. The number indicates the minimum limit of detection.

** Phosphorus concentrations measured by independent analysis may not be accurate.

Table 2. Mechanical Properties of Uniformily Tensile Prestrained and Cold Rolled Alloy 600 Plate Measured in the L Direction

\begin{tabular}{|c|c|c||}
\hline Specimen Prefix & Condition & Yield Strength (MPa) \\
\hline CB13, CB20 & $\begin{array}{c}\text { Annealed }\left(1075^{\circ} \mathrm{C} \text { for } 24 \text { hours, }\right. \\
\text { Furnace Cooled for } 24 \text { hours) }\end{array}$ & 201 \\
\hline S5 & Annealed and 3.5 percent Strain & 345 \\
\hline S16 & $\begin{array}{c}\text { Annealed and } 10.4,10.7, \\
\text { or } 11.4 \text { percent Strain }\end{array}$ & 489,513 or 517 \\
\hline S22 & $\begin{array}{c}\text { Annealed and } 17.0 \text { or } \\
17.3 \text { percent Strain }\end{array}$ & 630 or 633 \\
\hline S34 & Annealed and 25.7 percent Strain & 872 \\
\hline CR, LT, ST & Annealed and Cold Rolled to a 31.9 \\
percent Reduction
\end{tabular}




\begin{tabular}{|c|c|c|c|c|c|c|}
\hline \multicolumn{7}{|c|}{ Table 3. Alloy 600 SCC Growth Rate Results (LT Orientation) } \\
\hline Specimen & Orientation & $\begin{array}{c}\text { Temperature } \\
\left({ }^{\circ} \mathrm{C}\right)\end{array}$ & $\begin{array}{c}\text { Yield Strength } \\
\quad(\mathrm{MPa})\end{array}$ & $\begin{array}{c}\mathrm{K} \\
(\mathrm{MPa} \sqrt{\mathrm{m}})\end{array}$ & $\begin{array}{l}\mathrm{da} / \mathrm{dt} \\
(\mathrm{m} / \mathrm{s})\end{array}$ & $\begin{array}{l}\text { Loading Method/ } \\
\text { Hold Time (min) }\end{array}$ \\
\hline S34-50 & LT & 252 & 772 & 33.1 & $\mathrm{~N} / \mathrm{C}$ & Bolt \\
\hline CB20-61 & LT & 288 & 201 & 35.8 & $\mathrm{~N} / \mathrm{C}$ & Bolt \\
\hline S34-15 & LT & 288 & 772 & 34.2 & 2.19E-11 & Active (10) \\
\hline S16-43 & LT & 288 & 517 & 34.8 & $\mathrm{~N} / \mathrm{C}$ & Active (10) \\
\hline S22-19 & LT & 288 & 633 & 34.4 & $2.73 E-11$ & Active (10) \\
\hline CR28-10 & LT & 288 & 827 & 35.1 & $8.42 \mathrm{E}-11$ & Active (10) \\
\hline S34-22 & LT & 288 & 772 & 34.4 & $1.27 \mathrm{E}-11$ & Active (100) \\
\hline S16-50 & LT & 288 & 517 & 34.2 & 3.62E-12 & Active (100) \\
\hline S22-27 & LT & 288 & 633 & 34.0 & $1.27 \mathrm{E}-11$ & Active (100) \\
\hline CR28-20 & LT & 288 & 827 & 34.6 & 4.53E-11 & Active (100) \\
\hline CR28-11 & LT & 316 & 827 & 33.6 & 4.97E-11 & Active (10) \\
\hline S34-20 & LT & 316 & 772 & 34.5 & $4.31 \mathrm{E}-11$ & Active (10) \\
\hline $\mathrm{S} 22-20$ & LT & 316 & 633 & 34.6 & $5.00 \mathrm{E}-11$ & Active (10) \\
\hline S16-44 & LT & 316 & 517 & 34.5 & $2.05 E-11$ & Active (10) \\
\hline CR28-18 & LT & 316 & 827 & 34.9 & $2.39 E-11$ & Active (10) \\
\hline S22-23 & LT & 316 & 633 & 34.2 & $7.80 E-11$ & Active (10) \\
\hline S16-53 & LT & 316 & 517 & 33.7 & $2.74 E-11$ & Active (10) \\
\hline CR28-19 & LT & 316 & 827 & 35.7 & 1.81E-10 & Active (100) \\
\hline S22-29 & LT & 316 & 633 & 34.5 & $7.99 E-11$ & Active (100) \\
\hline S16-52 & $\mathrm{LT}$ & 316 & 517 & 33.7 & $1.83 \mathrm{E}-11$ & Active (100) \\
\hline LT1-14 & LT & 316 & 827 & 39.7 & $2.80 \mathrm{E}-10$ & Bolt \\
\hline LT1-16 & LT & 316 & 827 & 52.3 & 4.25E-10 & Bolt \\
\hline LT1-11 & LT & 316 & 827 & 21.6 & $9.82 E-11$ & Bolt \\
\hline LT1-15 & LT & 316 & 827 & 39.7 & $2.68 \mathrm{E}-10$ & Bolt \\
\hline LT1-13 & LT & 316 & 827 & 32.3 & $2.22 \mathrm{E}-10$ & Bott \\
\hline LT1-12 & LT & 316 & 827 & 21.1 & $9.69 \mathrm{E}-1 \mathrm{I}$ & Bolt \\
\hline CR28-5 & LT & 316 & 827 & 33.8 & $1.06 \mathrm{E}-10$ & Bolt \\
\hline CR28-6 & LT & 316 & 827 & 34.1 & $1.54 \mathrm{E}-10$ & Bolt \\
\hline CR28-8 & LT & 338 & 827 & 34.5 & 3.03E- 10 & Bolt \\
\hline CB20-63 & $L T$ & 338 & 201 & 35.7 & $N / C$ & Bolt \\
\hline S5-6 & LT & 338 & 345 & 38.2 & $1.83 E-10$ & Active (10) \\
\hline S16-12 & $\mathrm{LT}$ & 338 & 513 & 33.7 & 5.53E-11 & Bolt \\
\hline
\end{tabular}

N/C- No Cracking 
Page 12

\begin{tabular}{|c|c|c|c|c|c|c|}
\hline \multicolumn{7}{|c|}{ Table 3 (continued). Alloy 600 SCC Growth Rate Results (LT Orientation) } \\
\hline Specimen & Orientation & $\begin{array}{c}\text { Temperature } \\
\left({ }^{\circ} \mathrm{C}\right)\end{array}$ & $\begin{array}{l}\text { Yield Strength } \\
(\mathrm{MPa})\end{array}$ & $\begin{array}{c}\mathrm{K} \\
(\mathrm{MPa} \sqrt{\mathrm{m}})\end{array}$ & $\begin{array}{l}\mathrm{da} / \mathrm{dt} \\
(\mathrm{m} / \mathrm{s})\end{array}$ & $\begin{array}{l}\text { Loading Method/ } \\
\text { Hold Time (min) }\end{array}$ \\
\hline S16-10 & LT & 338 & 513 & 34.1 & $7.59 \mathrm{E}-11$ & Bolt \\
\hline S16-48 & LT & 338 & 517 & 33.3 & 2.65E-10 & Active (10) \\
\hline S22-16 & LT & 338 & 630 & 34.2 & $1.30 E-10$ & Bolt \\
\hline S22-24 & LT & 338 & 633 & 34.3 & $3.44 \mathrm{E}-10$ & Active (10) \\
\hline S16-11 & LT & 338 & 513 & 34.1 & $8.13 E-11$ & Bolt \\
\hline LT1-18 & LT & 338 & 827 & 32.0 & $4.03 E-10$ & Bolt \\
\hline LT1-17 & LT & 338 & 827 & 21.2 & $1.87 \mathrm{E}-10$ & Bolt \\
\hline LT1-19 & LT & 338 & 827 & 39.7 & $5.87 E-10$ & Bolt \\
\hline S16-47 & LT & 339 & 517 & 34.8 & $1.14 \mathrm{E}-10$ & Active (100) \\
\hline S22-25 & LT & 339 & 633 & 33.0 & $3.06 \mathrm{E}-10$ & Active (100) \\
\hline$S 16-13$ & LT & 358 & 513 & 33.6 & $1.52 \mathrm{E}-10$ & Bolt \\
\hline S22-17 & LT & 358 & 630 & 32.4 & $3.88 \mathrm{E}-10$ & Bolt \\
\hline S22-18 & LT & 358 & 630 & 33.0 & $5.06 \mathrm{E}-10$ & Bolt \\
\hline S5-12 & LT & 358 & 345 & 34.2 & $6.50 \mathrm{E}-11$ & Bolt \\
\hline$S 5-11$ & LT & 358 & 345 & 34.3 & $1.67 \mathrm{E}-10$ & Bolt \\
\hline S16-14 & LT & 358 & 513 & 30.1 & $1.91 \mathrm{E}-10$ & Bolt \\
\hline CR28-9 & LT & 358 & 827 & 33.1 & $6.98 \mathrm{E}-10$ & Bolt \\
\hline CB20-76 & LT & 360 & 201 & 30.2 & $5.79 E-11$ & Bolt \\
\hline CB20-73 & LT & 360 & 201 & 29.3 & 3.93E-11 & Bolt \\
\hline CB20-65 & LT & 360 & 201 & 35.2 & $5.01 \mathrm{E}-11$ & Bolt \\
\hline CB20-66 & LT & 360 & 201 & 35.4 & $5.56 \mathrm{E}-11$ & Bolt \\
\hline S5-10 & LT & 360 & 345 & 34.1 & 1.35E-10 & Bolt \\
\hline
\end{tabular}


Page 13

\begin{tabular}{|c|c|c|c|c|c|c|}
\hline Specimen & Orientation & $\begin{array}{c}\text { Temperature } \\
\left({ }^{\circ} \mathrm{C}\right)\end{array}$ & $\begin{array}{l}\text { Yield Strength } \\
\quad(\mathrm{MPa})\end{array}$ & $\begin{array}{c}\mathrm{K} \\
(\mathrm{MPa} \sqrt{\mathrm{m}})\end{array}$ & $\begin{array}{l}\mathrm{da} / \mathrm{dt} \\
(\mathrm{m} / \mathrm{s})\end{array}$ & Loading Method \\
\hline ST1-6 & ST & 252 & 827 & 54.7 & 4.72E-10 & Bolt \\
\hline ST1-15 & ST & 288 & 827 & 39.2 & $2.75 E-10$ & Bolt \\
\hline ST1-19 & ST & 288 & 827 & 53.2 & 3.33E-10 & Bolt \\
\hline ST1-16 & ST & 288 & 827 & 39.0 & $2.64 E-10$ & Bolt \\
\hline ST1-18 & ST & 288 & 827 & 52.7 & 8.06E-10 & Bolt \\
\hline ST1-10 & ST & 288 & 827 & 20.4 & $1.02 \mathrm{E}-10$ & Bolt \\
\hline ST1-9 & ST & 288 & 827 & 21.5 & $1.71 E-10$ & Bolt \\
\hline ST1-13 & ST & 288 & 827 & 32.2 & $2.68 E-10$ & Bolt \\
\hline$S T 1-11$ & ST & 288 & 827 & 21.4 & $6.61 \mathrm{E}-11$ & Bolt \\
\hline ST1-14 & ST & 288 & 827 & 31.9 & $8.90 E-11$ & Bolt \\
\hline ST1-17 & ST & 288 & 827 & 41.9 & $3.85 E-10$ & Bolt \\
\hline ST1-12 & ST & 288 & 827 & 32.0 & $1.16 E-10$ & Bolt \\
\hline ST1-20 & ST & 288 & 827 & 53.0 & $6.18 E-10$ & Bolt \\
\hline ST2-28 & ST & 316 & 827 & 40.9 & $1.71 \mathrm{E}-09$ & Boit \\
\hline ST2-30 & ST & 316 & 827 & 53.6 & 3.95E-09 & Bolt \\
\hline ST2-31 & ST & 316 & 827 & 49.1 & $3.14 \mathrm{E}-09$ & Bolt \\
\hline ST1-21 & ST & 316 & 827 & 21.4 & 1.37E-09 & Bolt \\
\hline ST2-27 & ST & 316 & 827 & 39.9 & 2.56E-09 & Bolt \\
\hline ST1-22 & ST & 316 & 827 & 21.6 & $5.68 \mathrm{E}-10$ & Bolt \\
\hline ST1-23 & ST & 316 & 827 & 21.2 & $5.78 E-10$ & Bolt \\
\hline ST1-24 & ST & 316 & 827 & 31.9 & $1.95 \mathrm{E}-09$ & Bolt \\
\hline ST2-25 & ST & 316 & 827 & 33.9 & $1.82 \mathrm{E}-09$ & Bolt \\
\hline ST2-26 & ST & 316 & 827 & 32.7 & 1.47E-09 & Bolt \\
\hline ST2-29 & ST & 316 & 827 & 41.7 & 2.37E-09 & Bolt \\
\hline ST2-34 & ST & 338 & 827 & 22.0 & $2.01 \mathrm{E}-09$ & Bolt \\
\hline ST2-32 & ST & 338 & 827 & 22.9 & $1.77 \mathrm{E}-09$ & Bolt \\
\hline ST2-35 & ST & 338 & 827 & 32.8 & $3.78 \mathrm{E}-09$ & Bolt \\
\hline ST2-39 & ST & 338 & 827 & 40.4 & $4.42 E-09$ & Bolt \\
\hline ST2-36 & ST & 338 & 827 & 31.0 & $3.58 E-09$ & Bolt \\
\hline ST2-37 & ST & 338 & 827 & 34.0 & 3.93E-09 & Bolt \\
\hline ST2-38 & ST & 338 & 827 & 38.5 & $3.60 \mathrm{E}-09$ & Bolt \\
\hline ST2-33 & $\overline{S T}$ & 338 & 827 & 22.2 & 1.57E-09 & Bolt \\
\hline ST2-41 & ST & 360 & 827 & 24.0 & $4.35 \mathrm{E}-09$ & Bolt \\
\hline ST2-42 & ST & 360 & 827 & 21.6 & $6.28 E-09$ & Bolt \\
\hline ST2-40 & ST & 360 & 827 & 24.8 & 5.57E-09 & Bolt \\
\hline
\end{tabular}




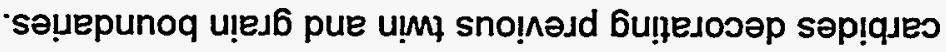

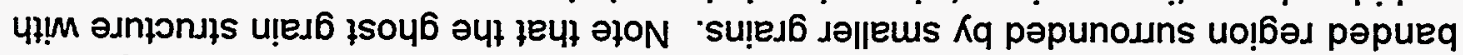

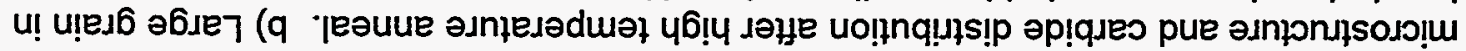

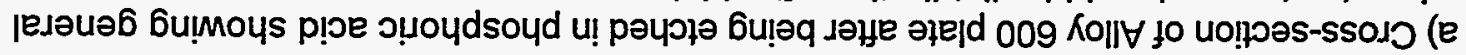
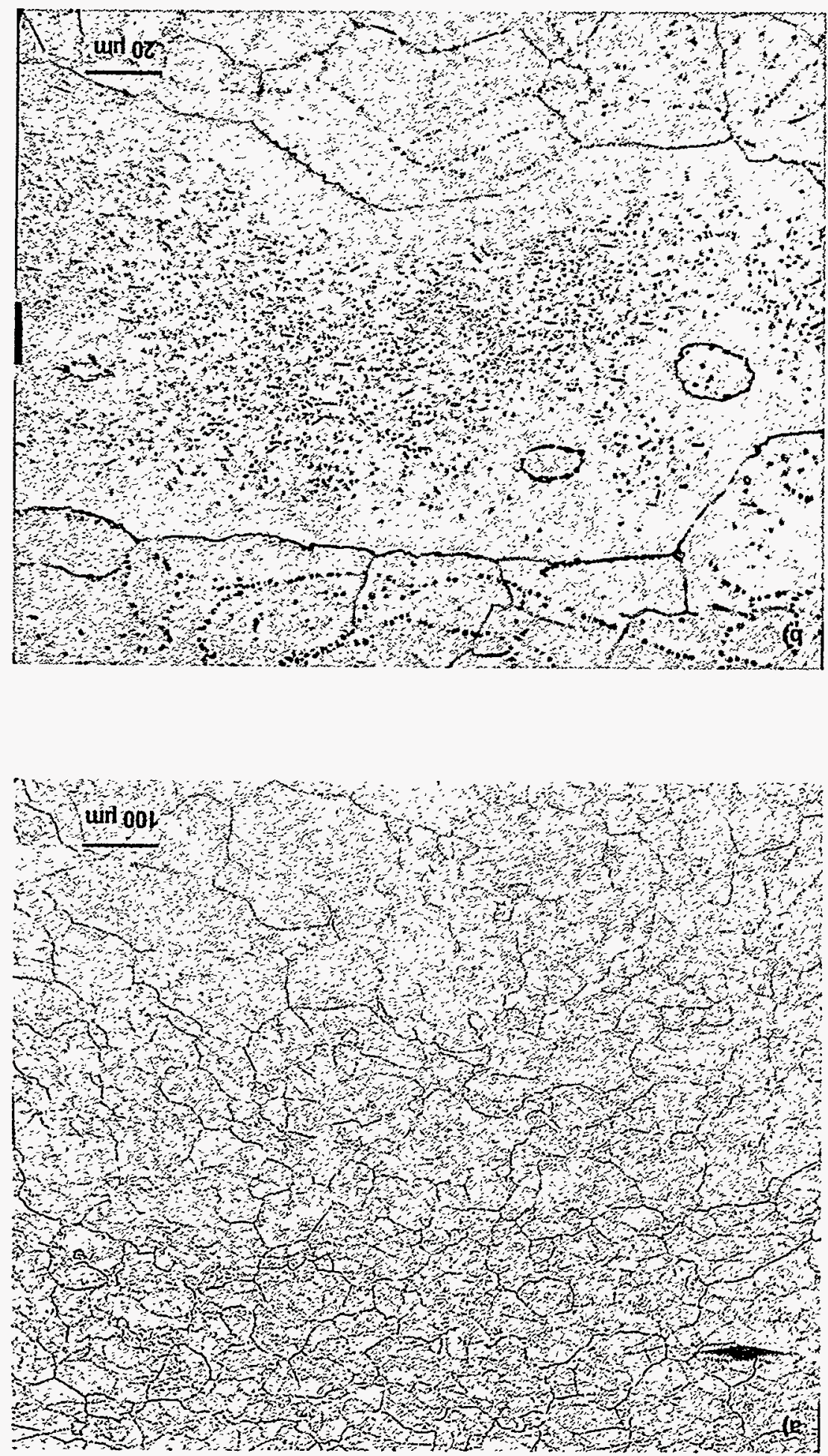

$\nabla \downarrow$ ə6ed 


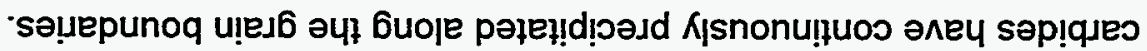

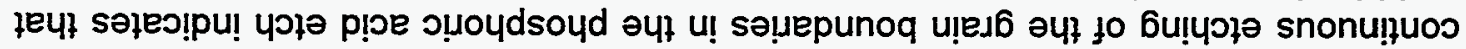

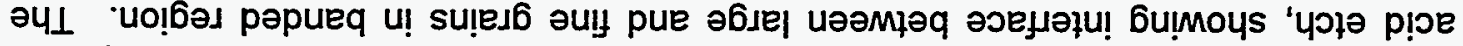

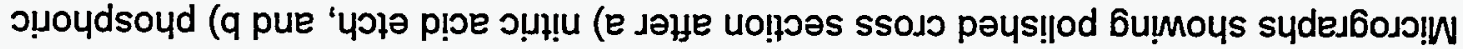
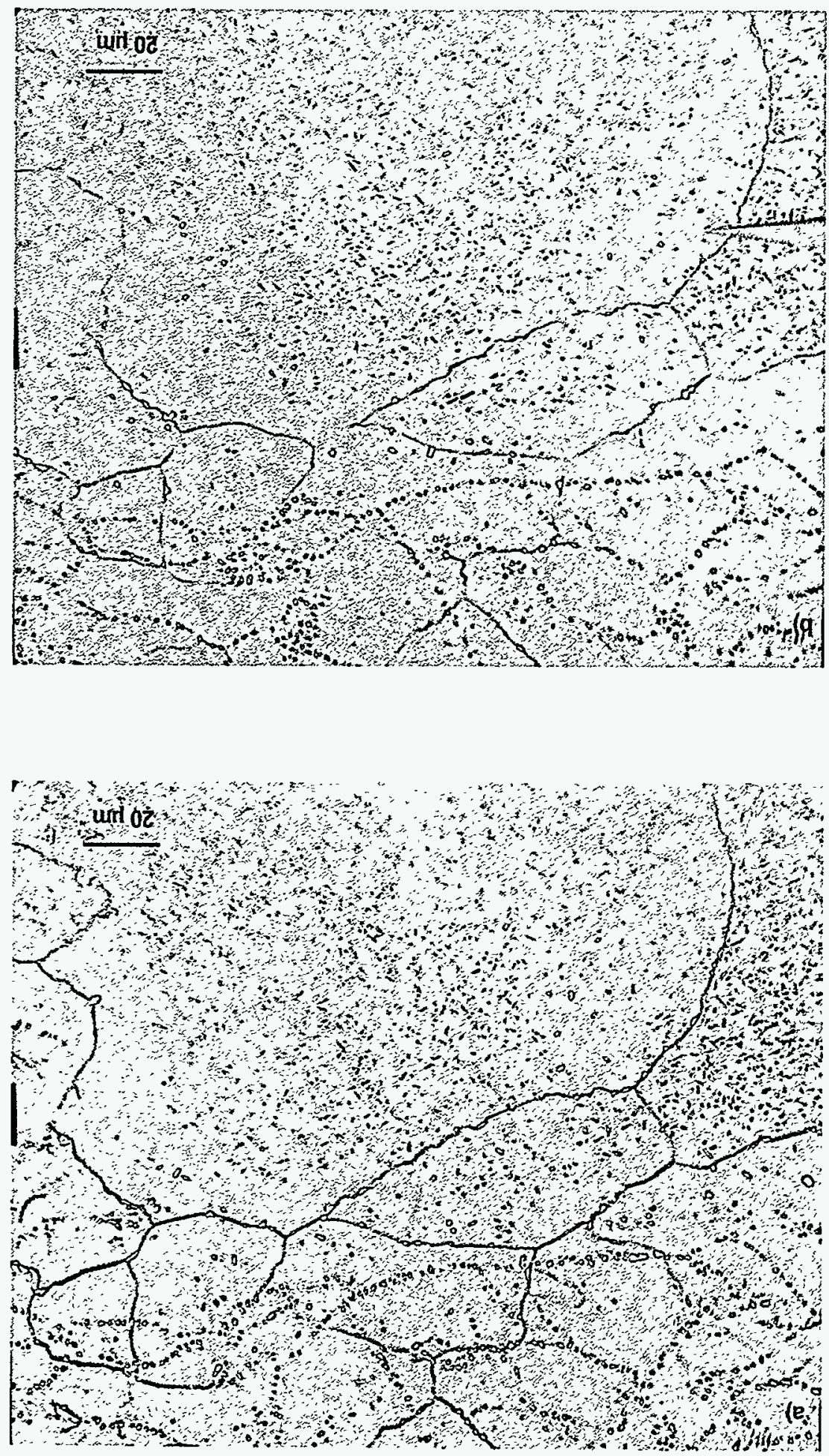


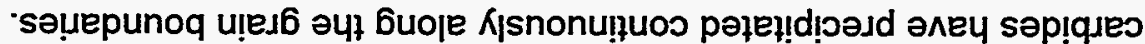

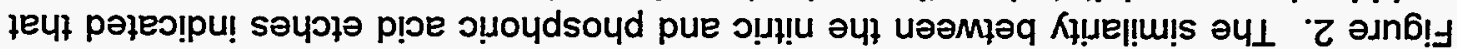

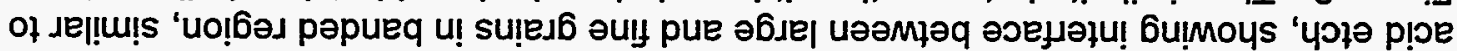

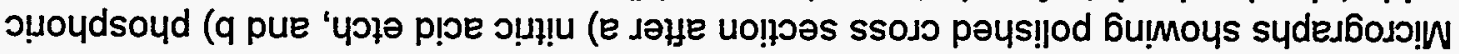
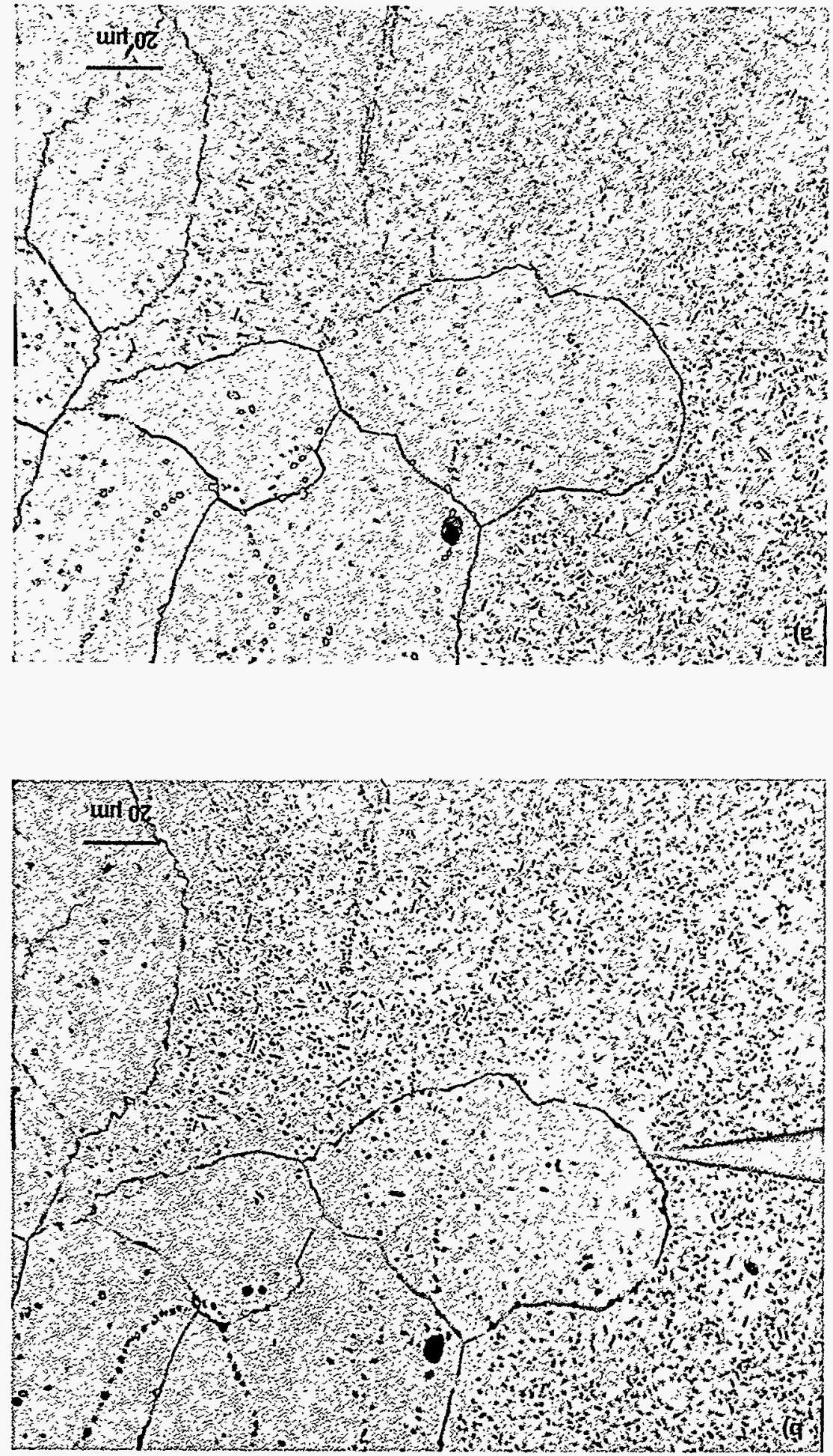

9เ әбed 

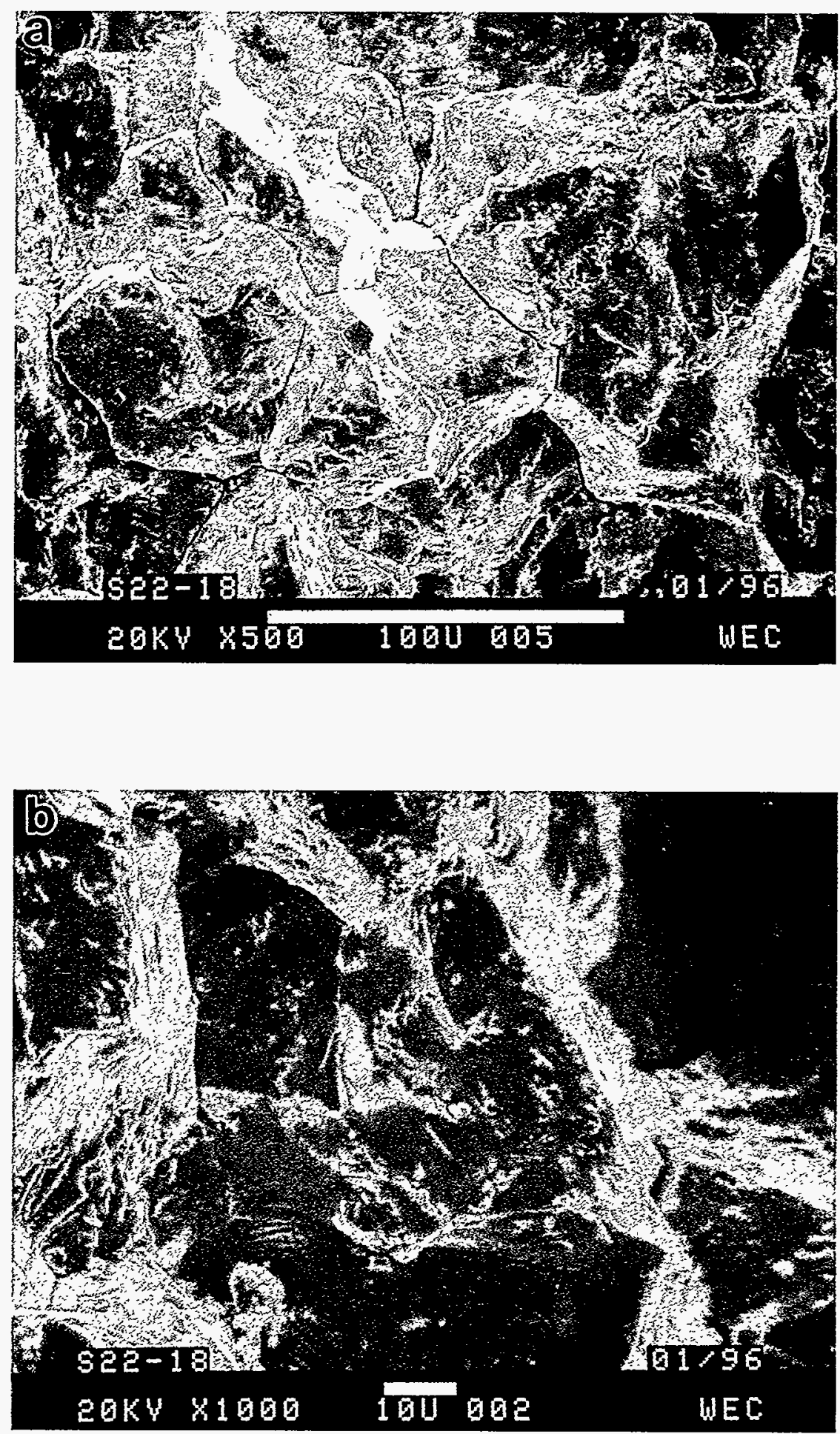

Figure 4. Fracture surface of SCC region from material with a yield strength of $634 \mathrm{MPa}$ tested at $360^{\circ} \mathrm{C}$ for 1254 hours showing a) intergranular fracture, and b) blocky carbides decorating the grain faces. 


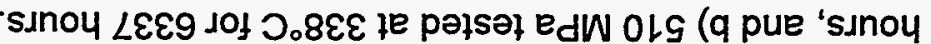

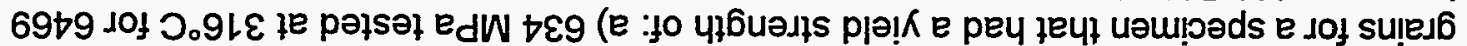

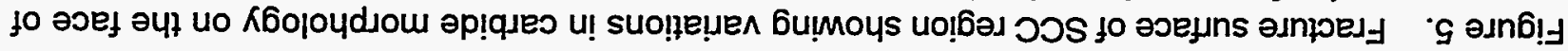
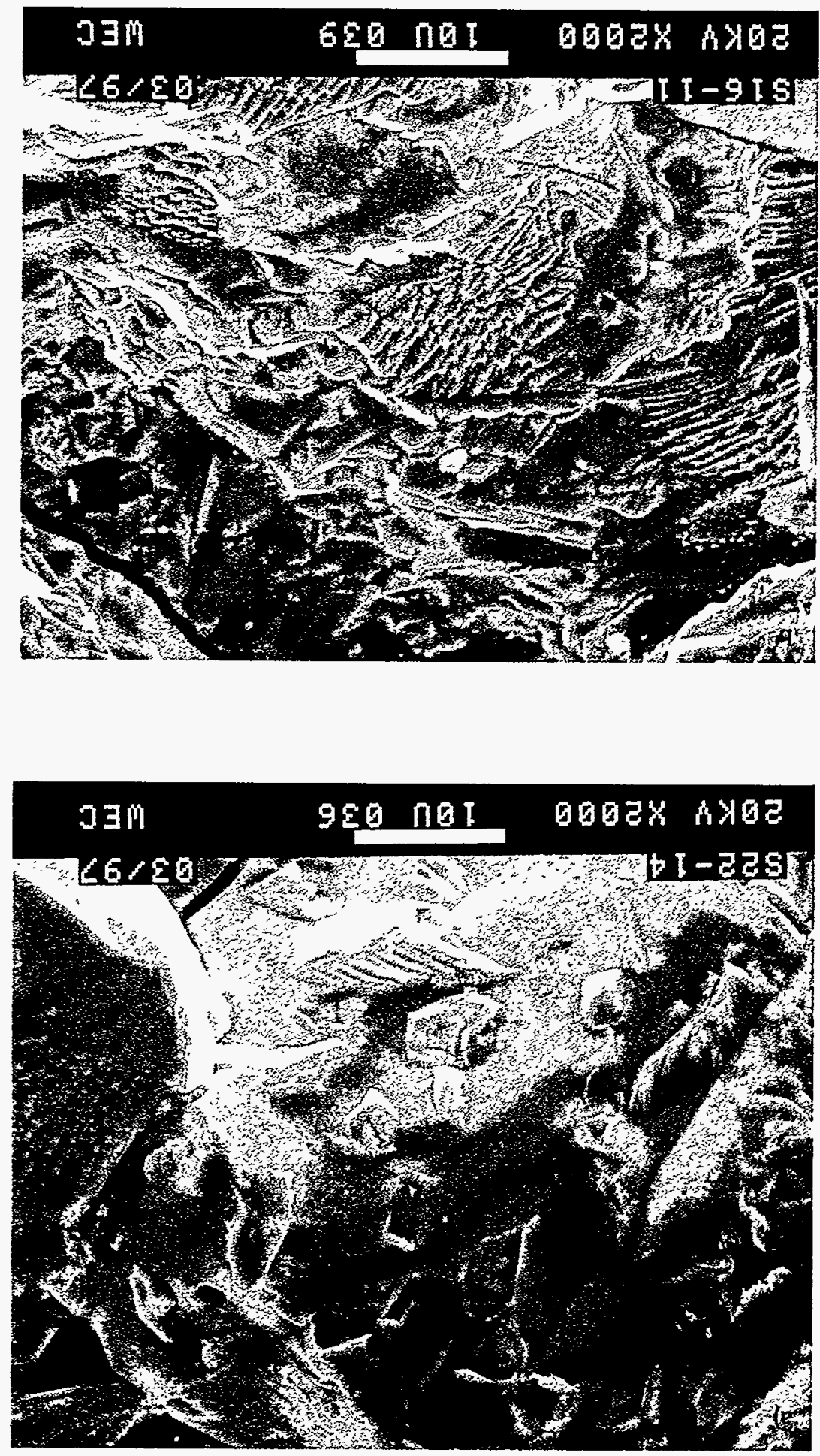

81 ə6ed 


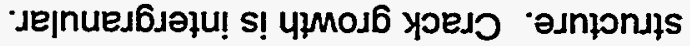

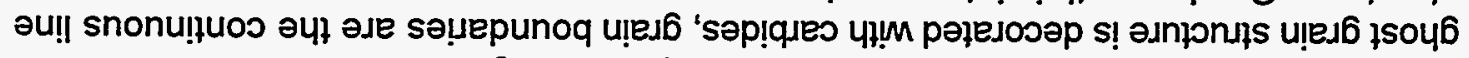

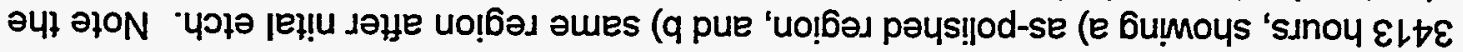

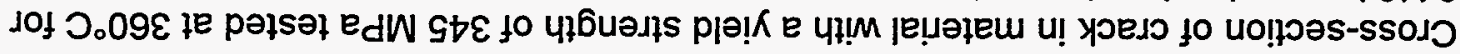

9 əנn6!

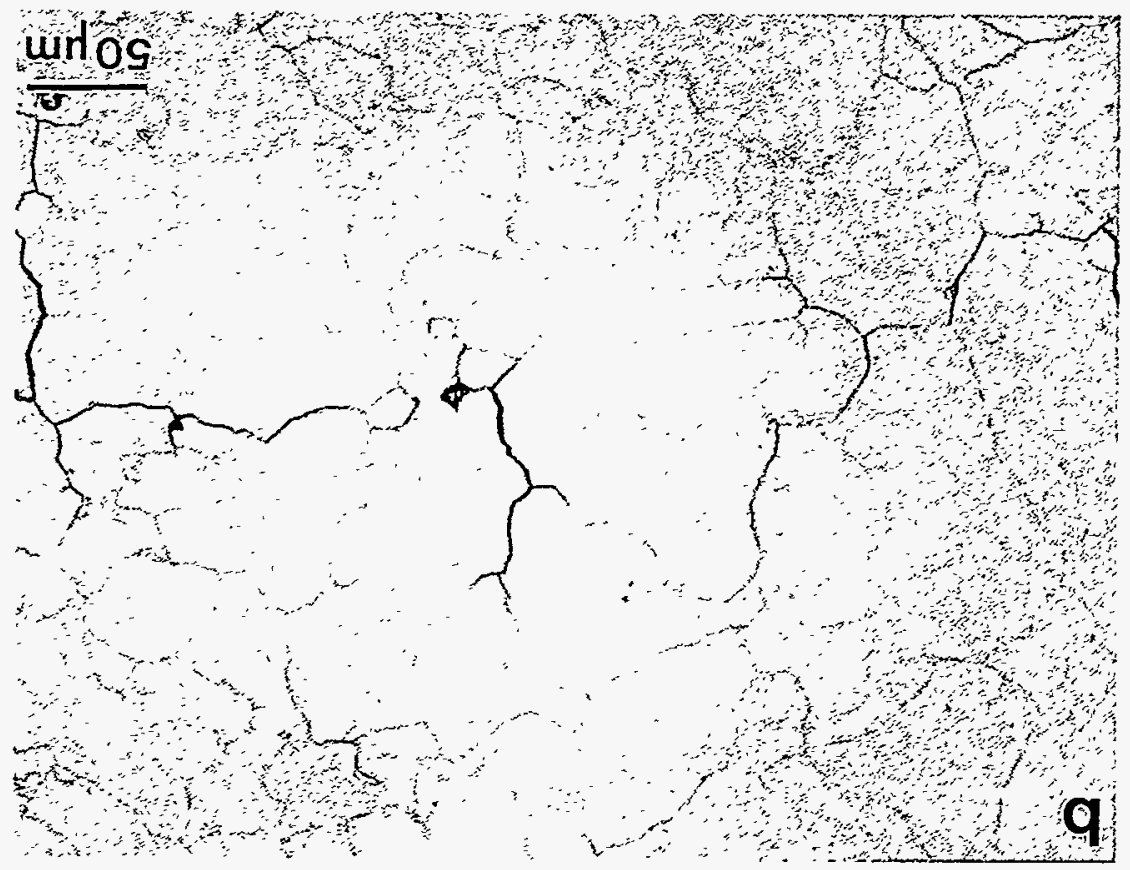

writos
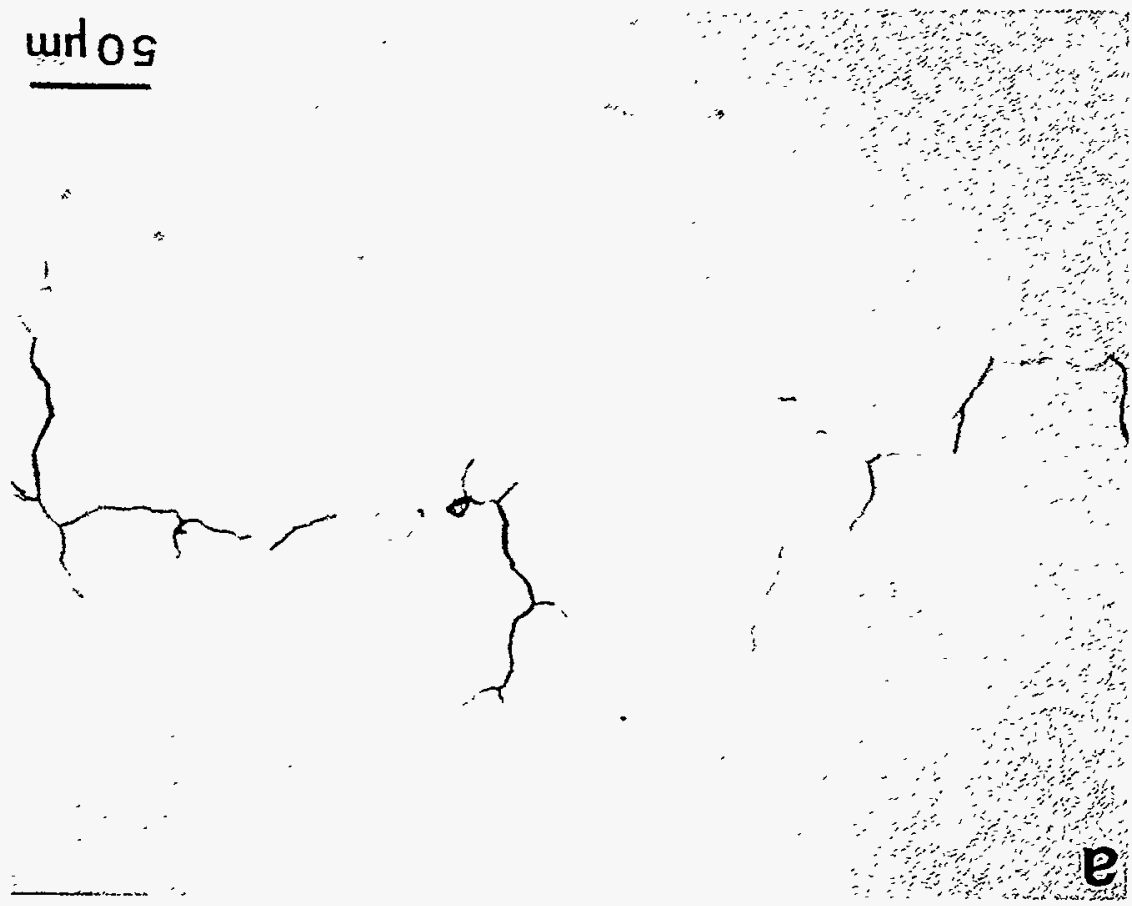

6L əбed 


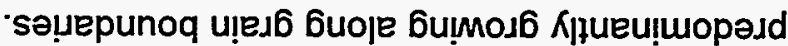

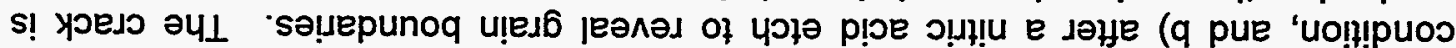

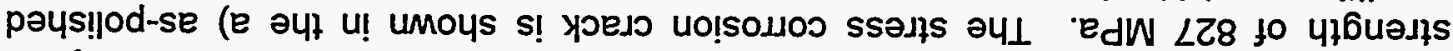

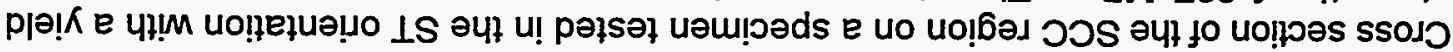
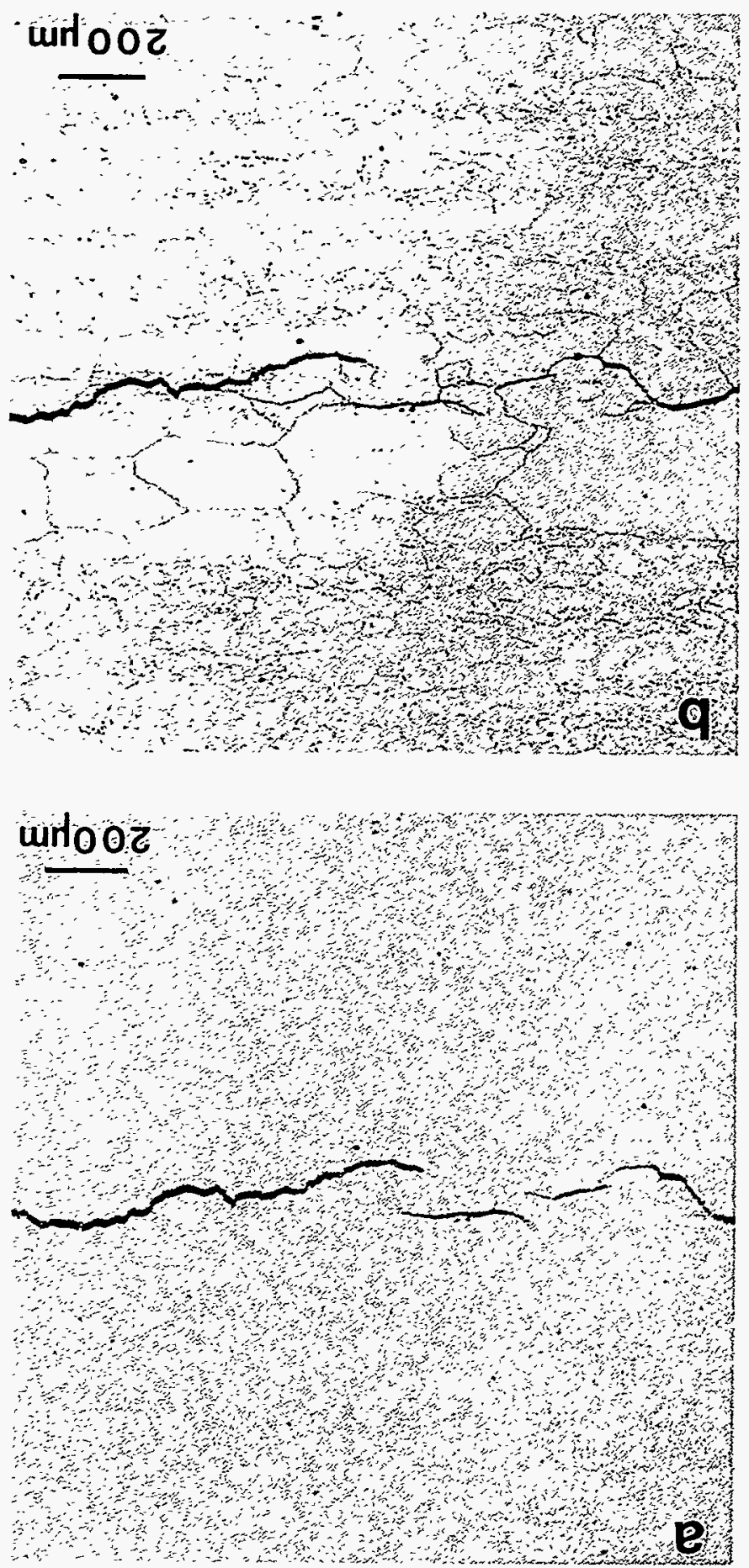

$0 z$ abed 
- Kuepunoq u!es6 әuł

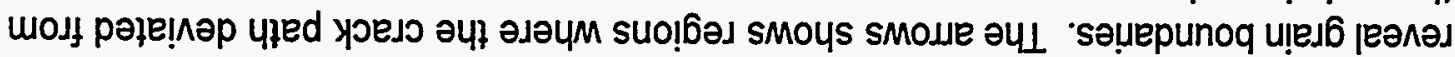

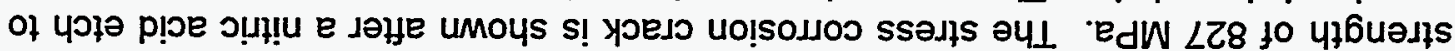

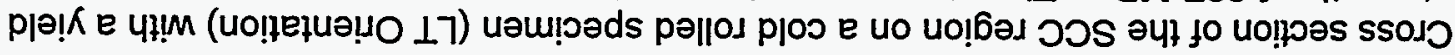

8 əมn6!

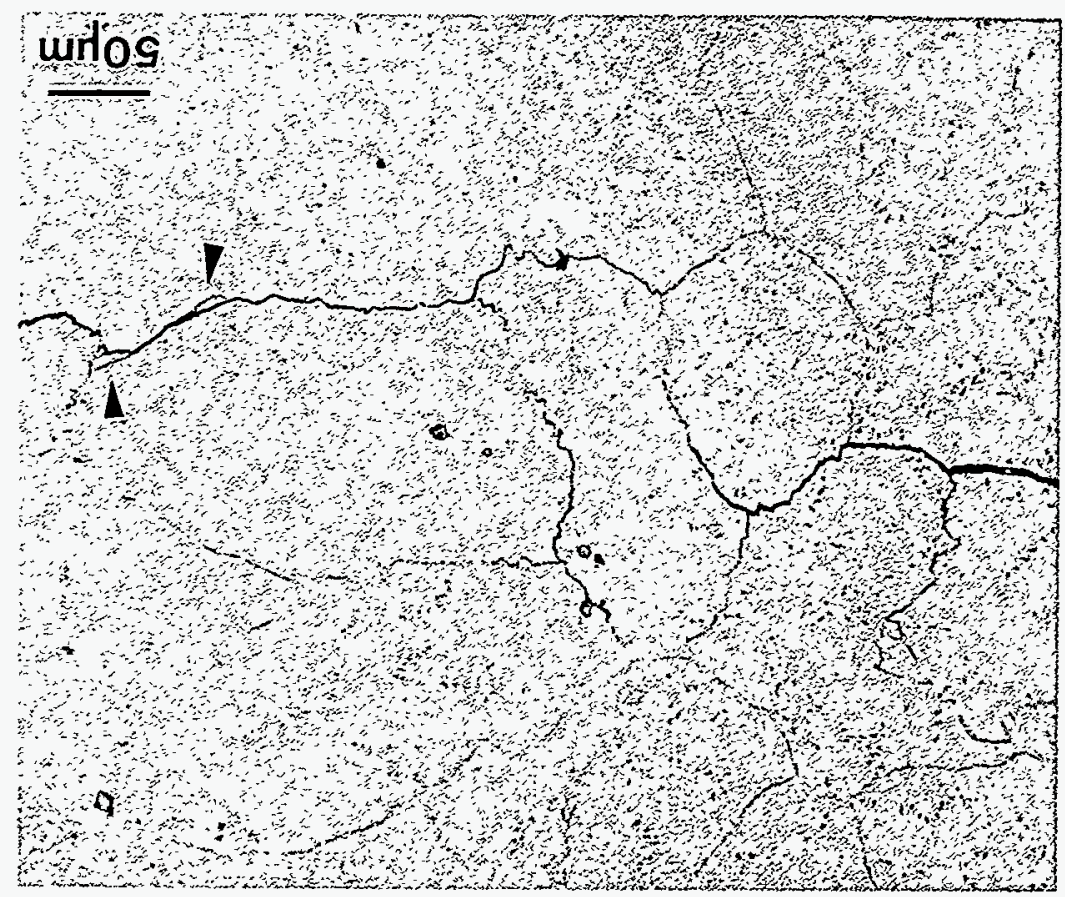

Ł乙 әбеd 

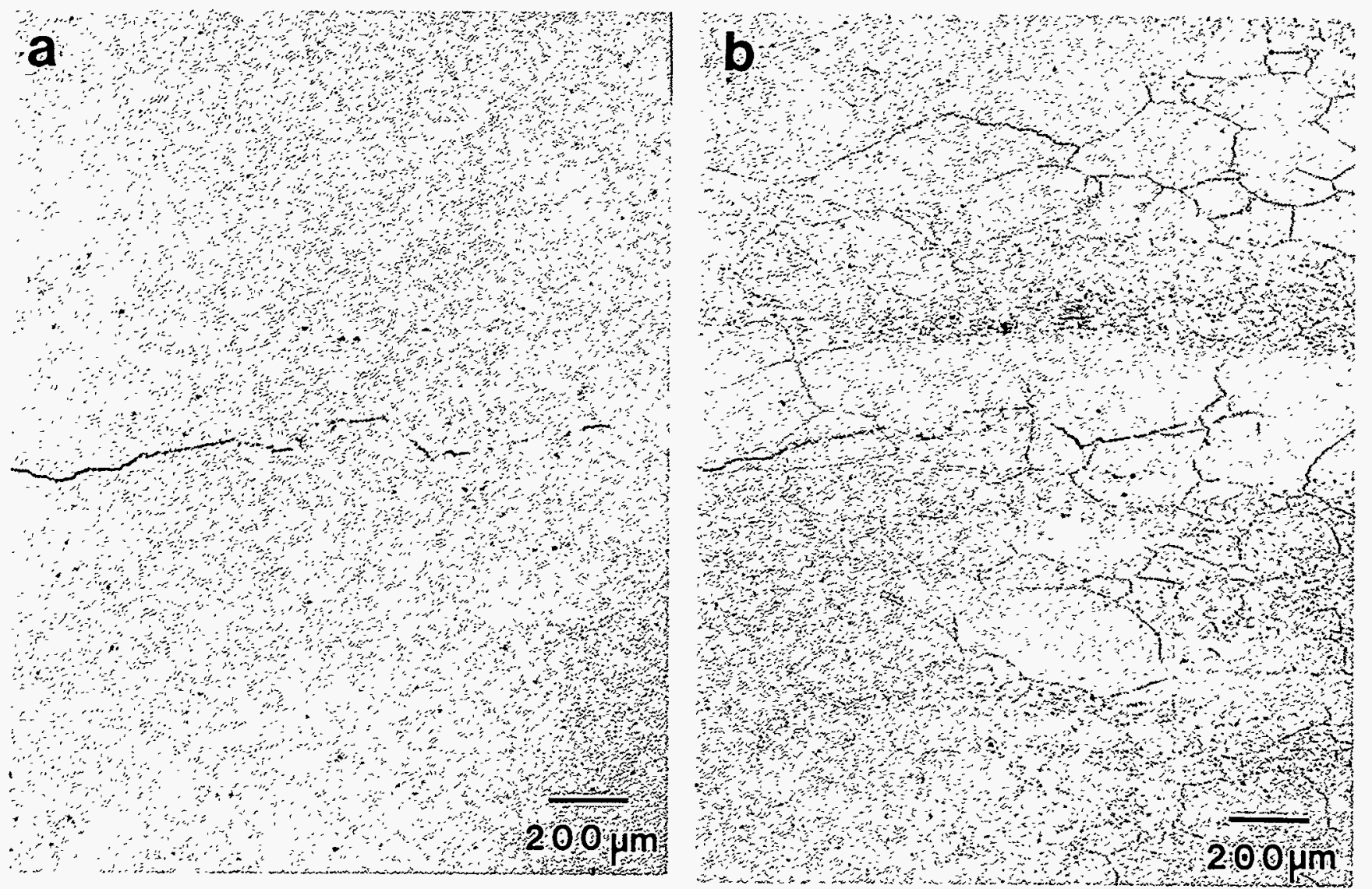

Figure 9. Cross section of the SCC region on a cold rolled specimen (ST Orientation) with a yield strength of $827 \mathrm{MPa}$. The stress corrosion crack is shown in the a) as-polished condition, and b) after a nitric acid etch to reveal grain boundaries. Crack growth is completely transgranular. 


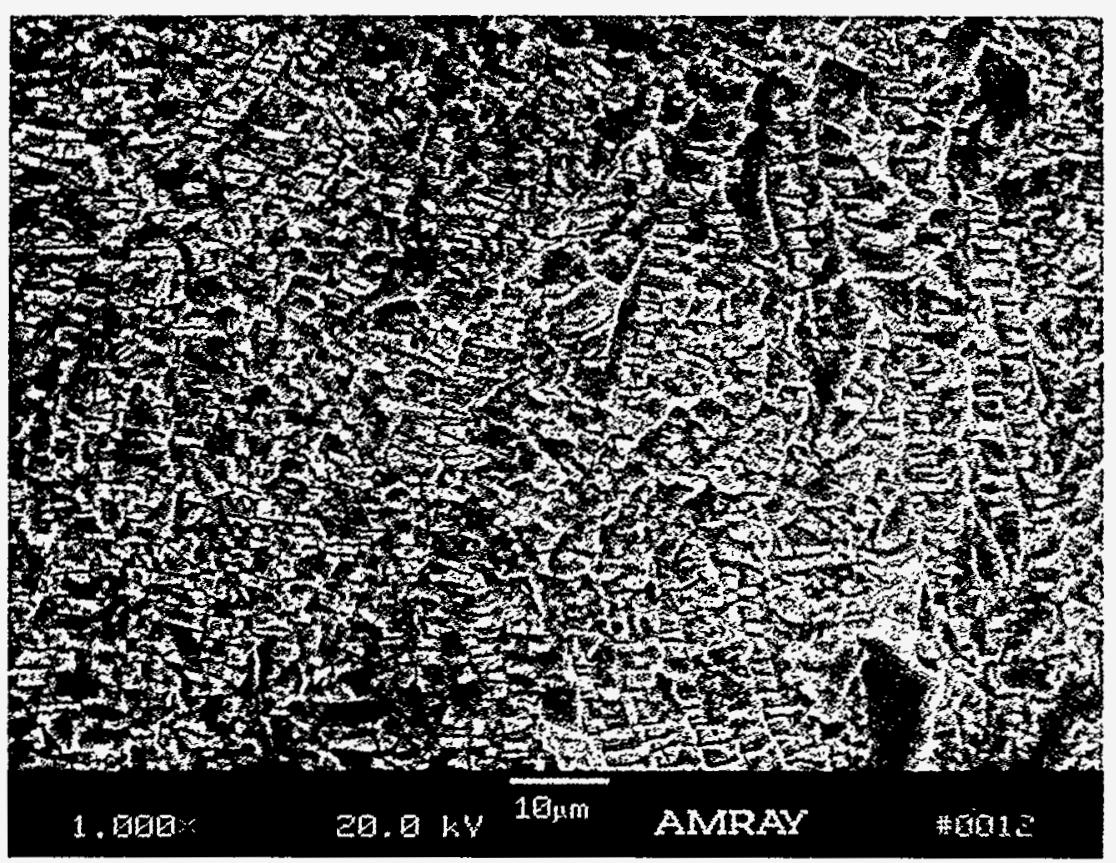

Figure 10. The fracture surface of the SCC region on a specimen with a yield strength of $827 \mathrm{MPa}$ tested in the $\mathrm{ST}$ orientation at $288^{\circ} \mathrm{C}$ and a $\mathrm{K}$ of $33 \mathrm{MPa} \sqrt{\mathrm{m}}$. Figure 9 shows that the fracture path was transgranular, and the fracture surface is covered with a series of poorly defined slip offsets. 


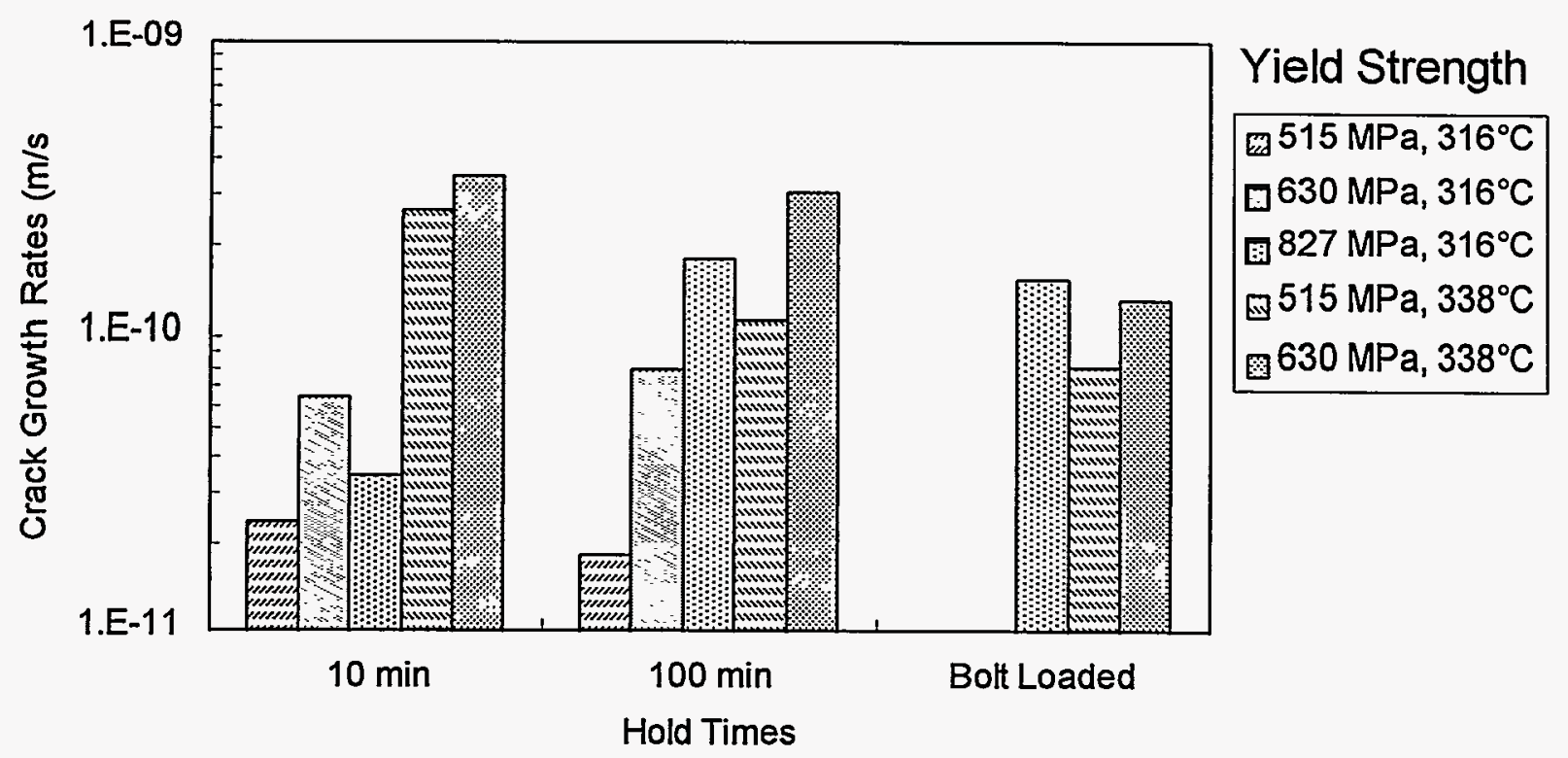

Figure 11. Effect of cyclic load on the SCCGR of cold worked Alloy 600 at 316 and $338^{\circ} \mathrm{C}$. Specimens were held at a constant load for either 10 or 100 minutes, and then cycled at a loading ratio of 0.7 for 1 minute. In general, cyclic loading may have slightly increased CGRs for lower yield strength material by up to a factor of two in comparison to CGRs determined from bolt-loaded specimens.

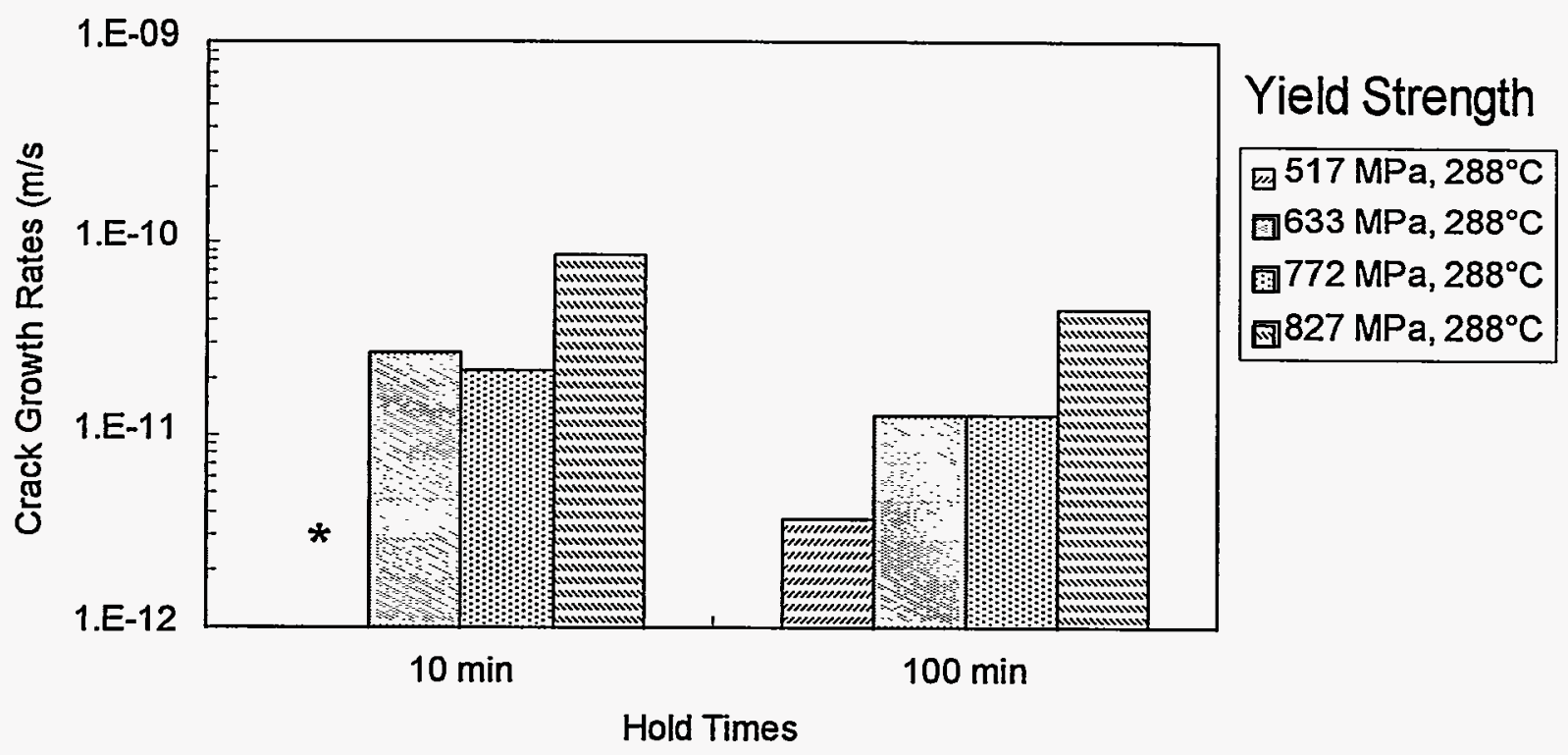

Figure 12. Crack growth rates measured at $288^{\circ} \mathrm{C}$ as a function of yield strength and hold time. The * denotes that no specimen was tested for this condition. Cyclic loading may have increased crack growth rates by up to a factor of two. No data is available on CGRs measured from the bolt-loaded specimens at $288^{\circ} \mathrm{C}$ in the LT orientation. 


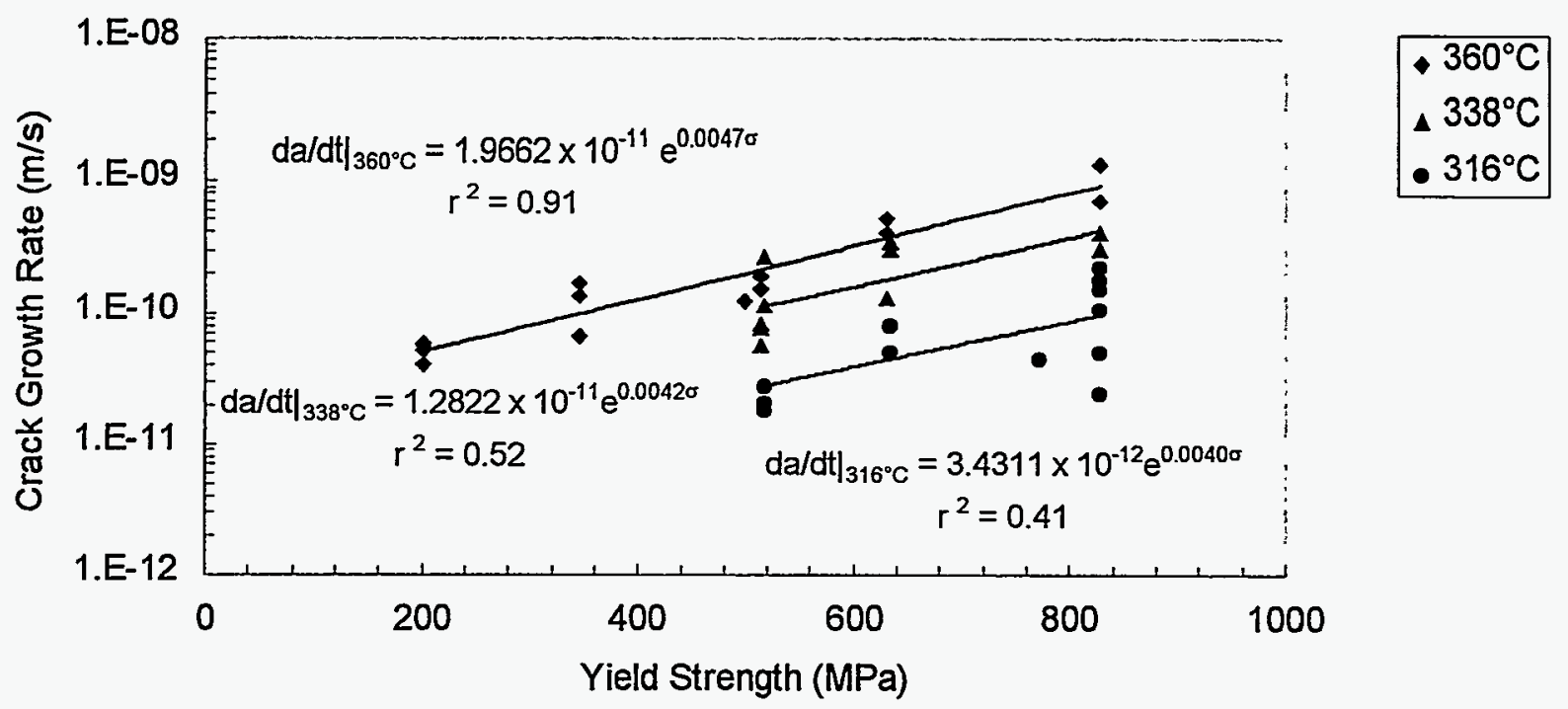

Figure 13. Effect of cold work on Alloy 600 SCC growth for specimens with cracks growing in the LT orientation. CGR data were obtained for specimens loaded between 28 and $35 \mathrm{MPa} \sqrt{\mathrm{m}}$ and over a temperature range between 316 and $360^{\circ} \mathrm{C}$.

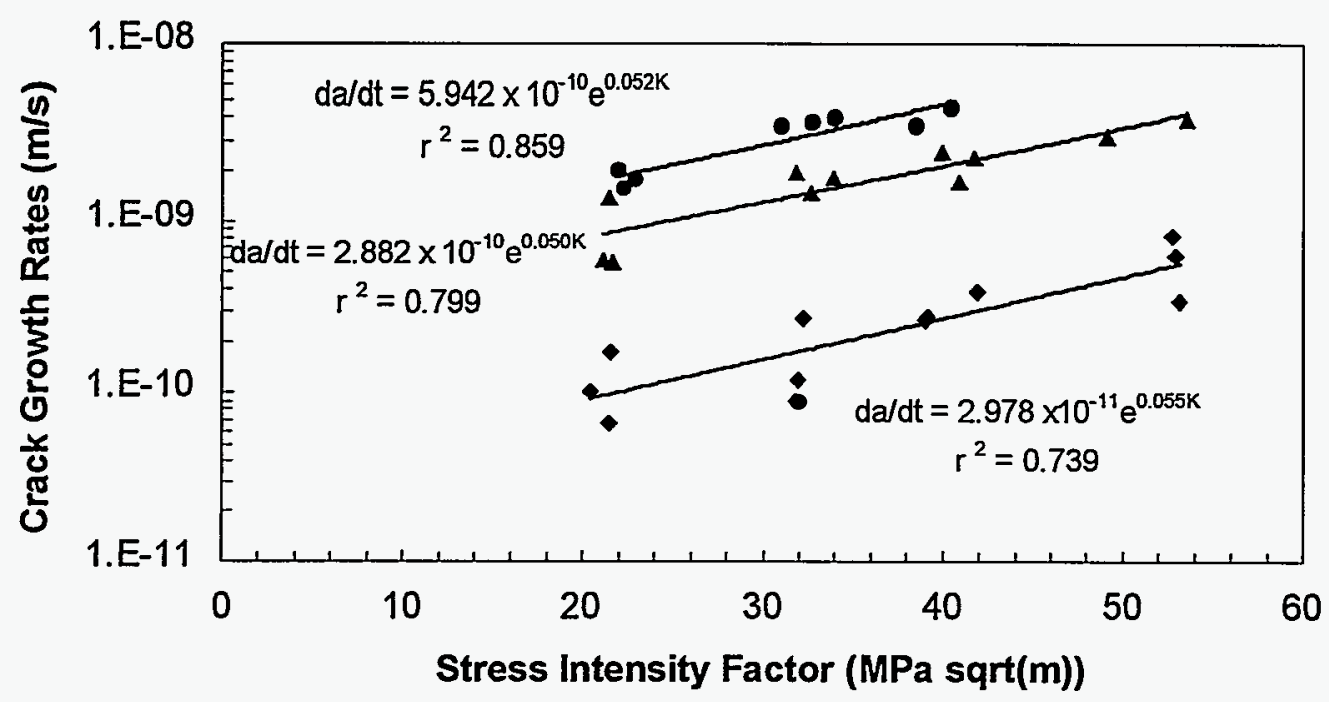

$\begin{array}{r}-338^{\circ} \mathrm{C} \\ -316^{\circ} \mathrm{C} \\ -288^{\circ} \mathrm{C} \\ \hline\end{array}$

Figure 14. SCC growth rate behavior of cold rolled Alloy 600 with a yield strength of $827 \mathrm{MPa}$ tested in the ST orientation over a temperature range between 288 and $338^{\circ} \mathrm{C}$. 


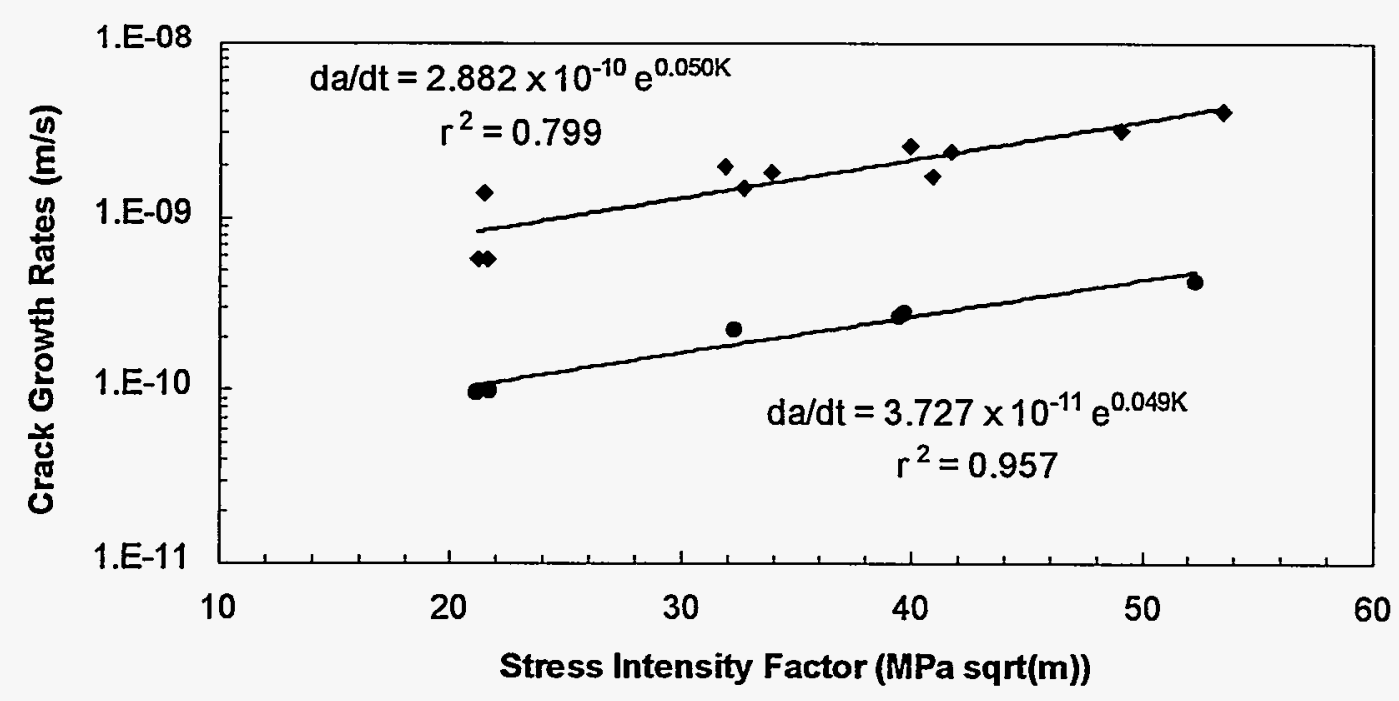

Figure 15. The effect of processing orientation (ST versus LT) on the SCC growth rate behavior of cold rolled Alloy 600 with a yield strength of $827 \mathrm{MPa}$ tested at $316^{\circ} \mathrm{C}$.

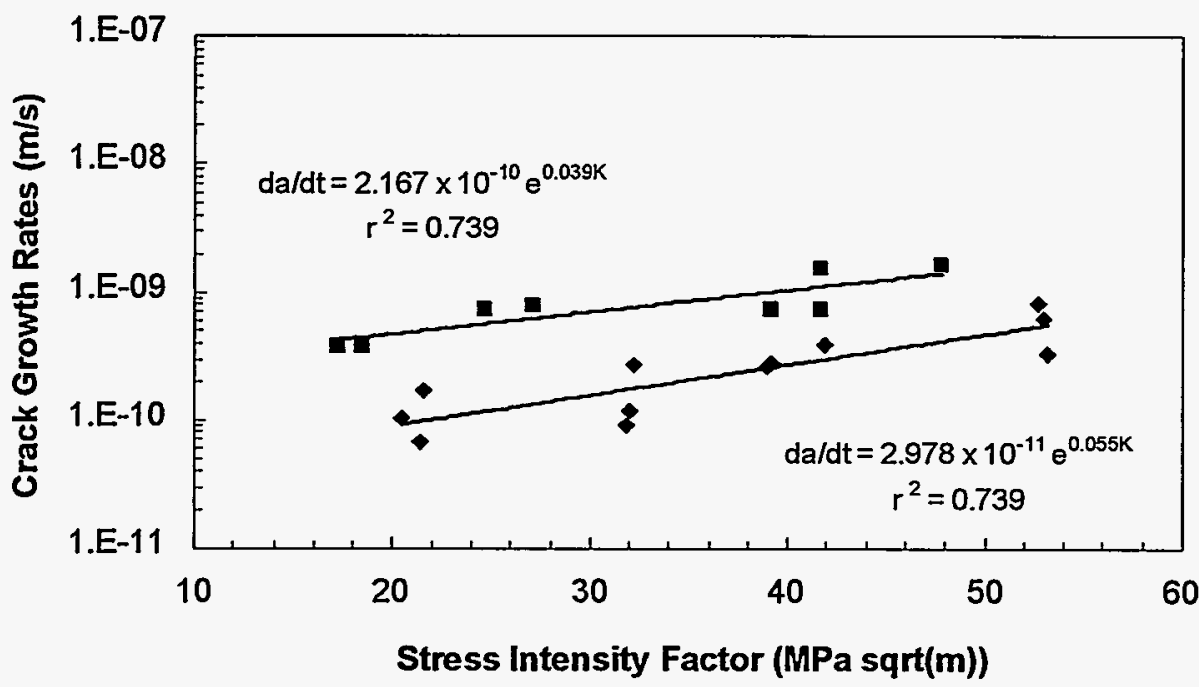

$+827 \mathrm{MPa}-\mathrm{ST}$
$.981 \mathrm{MPa}-\mathrm{CL}$

Figure 16. Comparison of the crack growth rate behavior of the cold rolled Alloy 600 plate used in this study ( $827 \mathrm{MPa})$ and the cold rolled Alloy 600 bar used in the work reported by Speidel and Magdowski (981 MPa). ${ }^{3}$ 


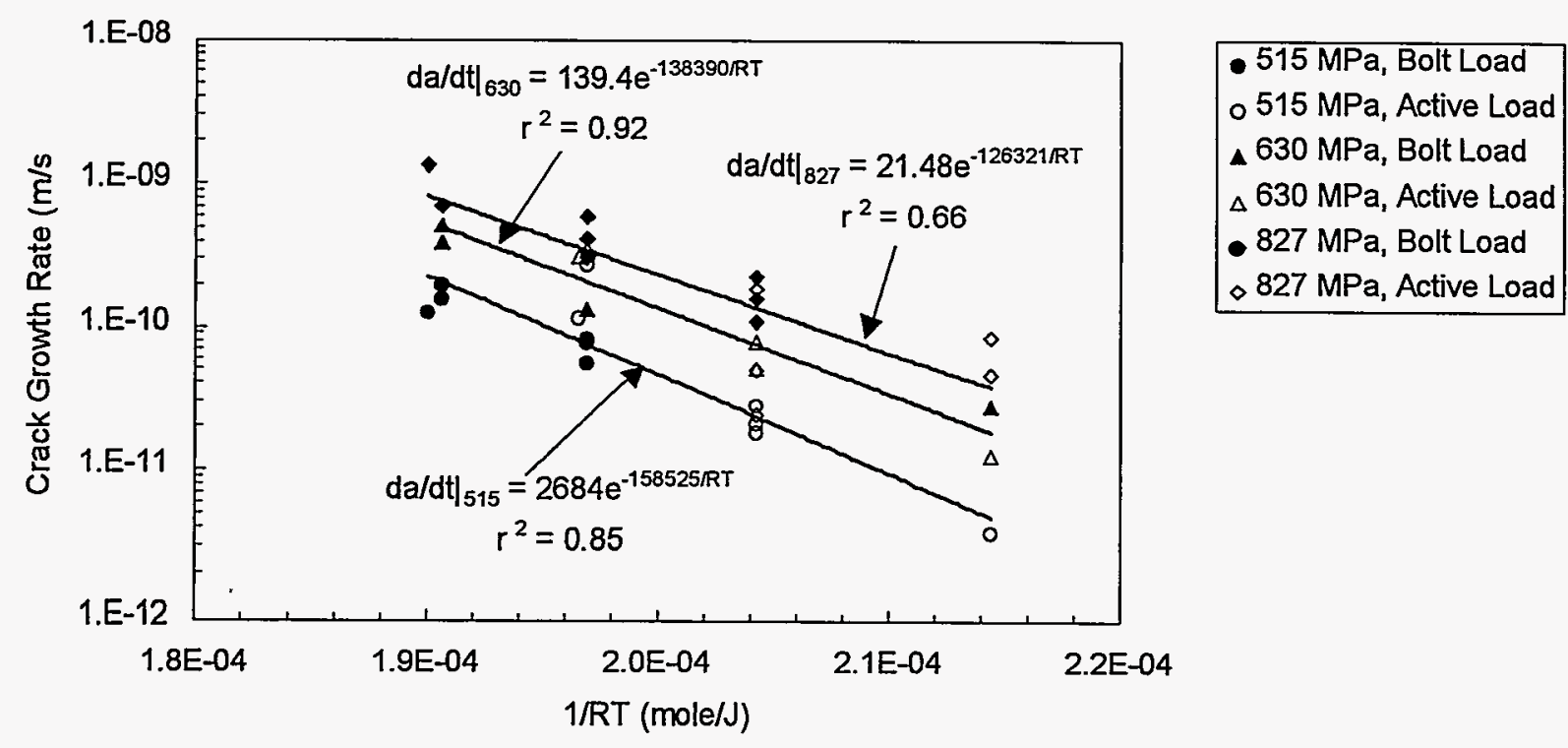

Figure 17. Activation energy for crack growth in the $L T$ orientation at $K \sim 32 \mathrm{MPa} \sqrt{\mathrm{m}}$ for tensile prestrained $(515$ and $630 \mathrm{MPa})$ and cold rolled $(827 \mathrm{MPa})$ material. The filled symbols are data from bolt-loaded tests, and the open symbols are data from actively-loaded tests.

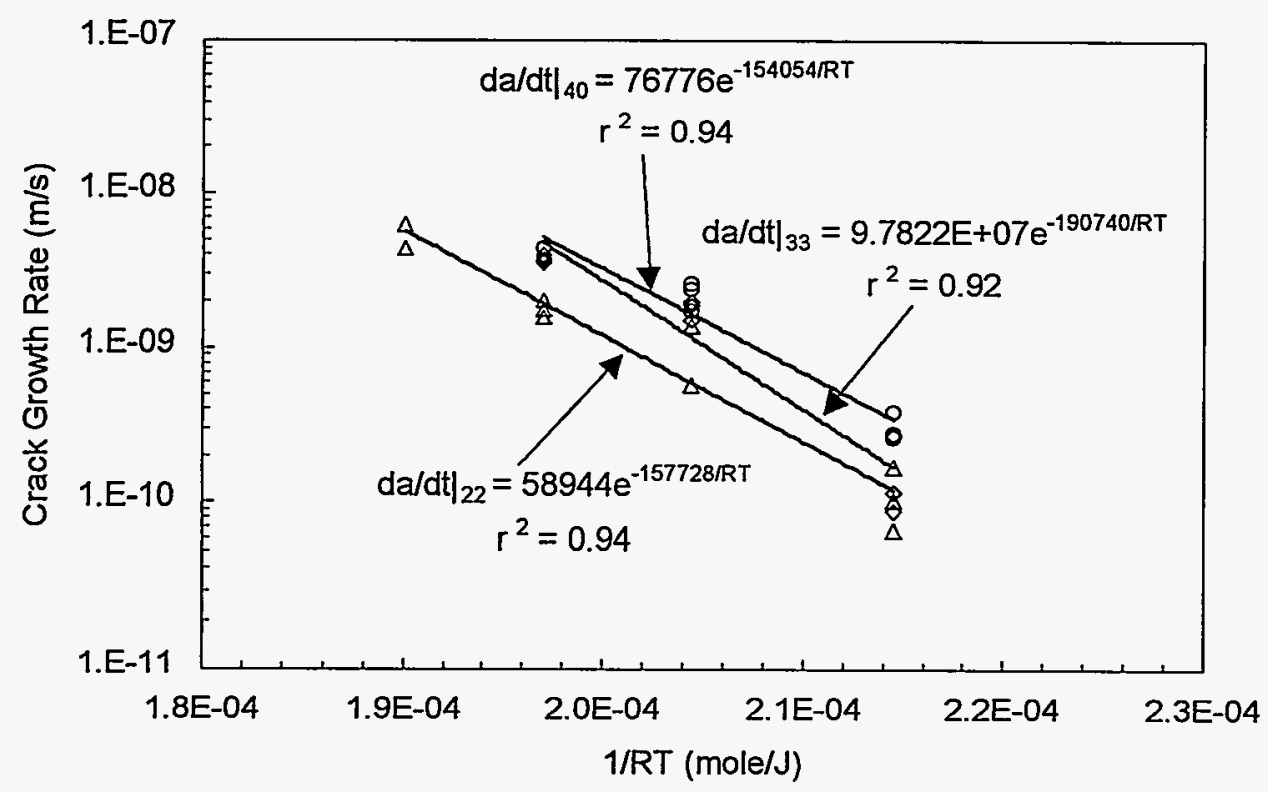

$\triangle \mathrm{K}=22 \mathrm{MPa}$ sqrt(m)
$\Delta \mathrm{K}=33 \mathrm{MPa}$ sqrt(m)
$0 \mathrm{~K}=40 \mathrm{MPa}$ sqrt(m)

Figure 18. Activation energies determined for specimens tested in the $\mathrm{ST}$ orientation at $\mathrm{K}=22$, 33 , and $40 \mathrm{MPa} \sqrt{\mathrm{m}}$. 